\title{
Facile synthesis toward the construction of an activity probe library for glycosidases
}

\author{
Tong-Hong Shie, ${ }^{a}$ Ying-Ling Chiang, ${ }^{a}$ Jing-Jer Lin, ${ }^{b, *}$ Yaw-Kuen Li ${ }^{\mathrm{c}}$ \\ and Lee-Chiang $\mathrm{Lo}^{\mathrm{a}, *}$ \\ ${ }^{a}$ Department of Chemistry, National Taiwan University, Taipei 106, Taiwan \\ ${ }^{\mathrm{b}}$ Institute of Biopharmaceutical Sciences, National Yang-Ming University, Taipei 112, Taiwan \\ ${ }^{\mathrm{c}}$ Department of Applied Chemistry, The National Chiao Tung University, Hsinchu 300, Taiwan \\ Received 4 October 2005; received in revised form 29 November 2005; accepted 14 December 2005 \\ Available online 18 January 2006
}

\begin{abstract}
Chemical probes that selectively label the glycoside hydrolase $(\mathrm{GH})$ subfamilies have proven to be a powerful tool in GHrelated research. We have previously demonstrated the design and synthesis of an activity probe for $\beta$-glucosidase adopting a cassette-like design in a model study. Herein we report an improved synthetic route using (4-hydroxyphenyl)acetic acid 2-cyanoethyl ester as the precursor for the latent trapping device. Parallel syntheses were performed for the preparation of a library based on the structure of a key intermediate. The recognition head of this library covers a series of six sugars, including $\alpha$ - and $\beta$-D-Glc, $\alpha$ - and $\beta$ D-Gal, $\alpha$-D-Man, and $\alpha$-L-Fuc. Each member in this versatile intermediate library could serve as the building block in constructing an activity probe for GHs. As demonstrated in this study, three probes that have the 1,2-cis configuration were thus prepared for the first time to target $\alpha$-D-glucosidase, $\alpha$-D-galactosidase, and $\alpha$-L-fucosidase, respectively.
\end{abstract}

(C) 2006 Elsevier Ltd. All rights reserved.

Keywords: Activity probe; Glycosidase; Proteomics; Hydrolase; Carbohydrate; Mechanism-based labeling; Biotin

\section{Introduction}

Glycoconjugates on the cell surface play important roles in many biological events, including viral infection, cellcell recognition, and protein trafficking. ${ }^{1-4}$ The carbohydrate signal molecules of these glycoconjugates are produced by sequential actions of designated glycosyltransferases and glycosidases. ${ }^{5,6}$ Dysfunction of these key enzymes often leads to detrimental situations. Due to their biological significance, glycoside hydrolases (GHs, glycosidases; EC 3.2.1) have become targets of interest in numerous interdisciplinary research fields. ${ }^{7-9}$ Currently, researchers are interested not only in the relative amount of the GHs, but also in the level of their activities. Chemical probes that selectively react with protein subfamilies through covalent interactions have

\footnotetext{
* Corresponding authors. Tel.: +8862 33661669; fax: +886223636359 (L.-C.L.); e-mail: 1clo@ntu.edu.tw
}

proven to be a powerful tool in modern chemical proteomics. ${ }^{10-13}$ This approach is especially useful for the hydrolase families as the labeling process matches well with the catalytic mechanism. For example, activity probes for GHs have been successfully applied in a wide variety of research, such as the screening and selection of catalytic antibodies, profiling of $\mathrm{GH}$ activity in proteomics studies, and investigation of active-site structures. ${ }^{14-19}$ In view of the great potential of activity probes for $\mathrm{GH}$ families, we envision that a systematic preparation of these probes would open new opportunities and accelerate the progress in GH-related research.

Recently, deoxyfluoro sugar derivatives bearing suitable reporter groups, which were able to form stable glycosyl-enzyme intermediates, have been incorporated into probe design to investigate glycosidases. ${ }^{18,19}$ However, this strategy is only applicable to the retaining glycosidases. As an alternative, we have previously adopted 


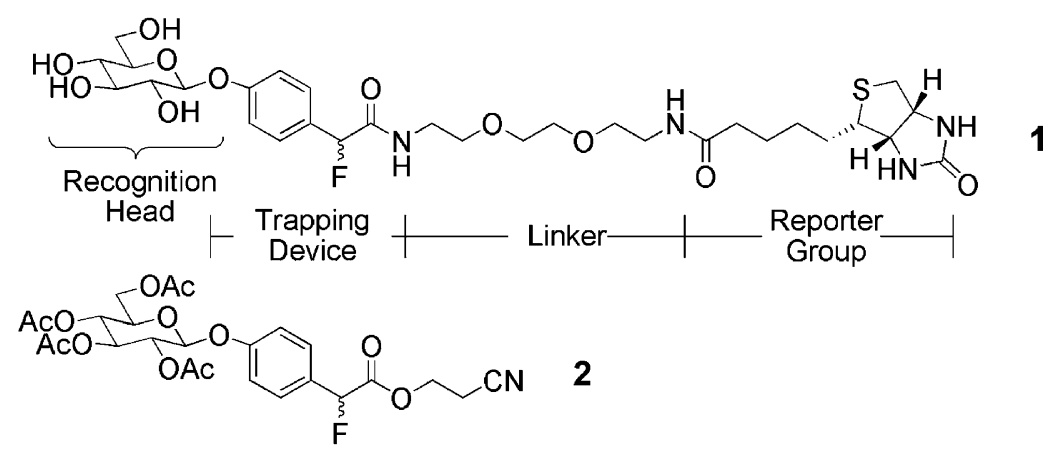

Figure 1. Structures of probe $\mathbf{1}$ and the key intermediate $\mathbf{2}$.

a suicide substrate-based approach and developed activity probes for hydrolases such as tyrosine phosphatases and GHs. ${ }^{16,20,21}$ Compound $\mathbf{1}$ was shown to be an activity probe for $\beta$-glucosidase in a model study, and compound 2, which already carries a recognition head linked to the latent trapping device, was a key synthetic intermediate (Fig. 1). ${ }^{16}$ In this report, we develop an improved synthetic route to construct a versatile library based on the structure of intermediate 2 . The recognition head of the library covers commonly six sugars and anomeric configurations, including both $\alpha$ and $\beta$ anomers of D-Glc and D-Gal as well as $\alpha$-D-Man and $\alpha$-L-Fuc. It has to be noted that, due to synthetic convenience, activity probes for GHs reported to date are limited to those that have the 1,2-trans configuration at the anomeric carbon. Herein we demonstrate the usefulness of such a library by preparing three activity probes for GHs with the 1,2-cis configuration.

\section{Results and discussion}

\subsection{Library design and labeling mechanism}

A typical activity probe carries two key structural elements in its design, namely, a reactive unit and a reporter group. Various reporter groups have been incorporated in the probe design in order to achieve different experimental goals. For example, fluorescent dyes and biotin are commonly used to monitor and help characterize the labeled proteins. Probe 1 consists of four structural units in its design, including a $\beta$-D-Glc recognition head, a latent trapping device, and a biotin reporter group connected through a linker bridge. The synthesis of probe 1 was accomplished in a cassette-like manner. Intermediate $\mathbf{2}$ is not only the core of the probe, but is also a versatile building block for future applications, depending on the property of the chosen reporter group. Therefore, the basic structure of intermediate $\mathbf{2}$ is well suited for library construction. In this study, we carried out parallel syntheses to prepare a building block library by simply replacing the $\beta$-D-Glc moiety with other glycosyl units. In the context, we used a letter following the compound number to specify both sugar identity and anomeric configuration of the recognition head for the series of compounds in the library synthesis; a for $\alpha$-D-Glc, b for $\alpha$-D-Gal, $\mathbf{c}$ for $\alpha-\mathrm{L}-\mathrm{Fuc}, \mathbf{d}$ for $\beta$-D-Glc, e for $\beta$-D-Gal, and $\mathbf{f}$ for $\alpha$-D-Man.

The design principle for an activity probe is similar to that for a suicide substrate of enzymes, except that a reporter group is attached to the activity probe. What is unique in this approach is that the probes themselves are also the substrates of the target hydrolases, resulting in high specificity toward the targets. The activation and alkylation process is depicted in Scheme 1. Generally, an activity probe $\mathbf{3}$ is stable under incubation conditions in the absence of the corresponding GH. However, when the glycosidic bond between the sugar unit and the latent trapping device is cleaved by the target $\mathrm{GH}$, it releases intermediate 4 , which quickly undergoes 1,6elimination to generate quinone methide 5. The highly reactive quinone methide $\mathbf{5}$ then reacts with suitable nucleophiles on nearby $\mathrm{GH}$ molecules to produce labeled adduct $\mathbf{6}$. As of this date, only a limited number of chemical structures are eligible for the latent trapping device of the activity probes. ${ }^{14-16,20,21}$ The quinone methide 5 utilized in this study was previously shown to preferably react with cysteine residues on target proteins. $^{22}$ However, no comparative study on the performance of these latent trapping devices has ever been reported.

\subsection{Retrosynthetic analysis}

The synthesis of the building block library 7 was divided into two stages. The retrosynthetic analysis is shown in Scheme 2. The first stage involves the preparation of glycosidation products $\mathbf{8}$. In recent years, progress in glycosidation reactions with a high degree of control of the anomeric configuration has been made by manipulating the properties of the participants in the glycosidation step, including the glycosyl donor, protective group, solvent and promoter. ${ }^{23-27}$ However, in order to achieve this high selectivity, special reagents needed for the reac- 


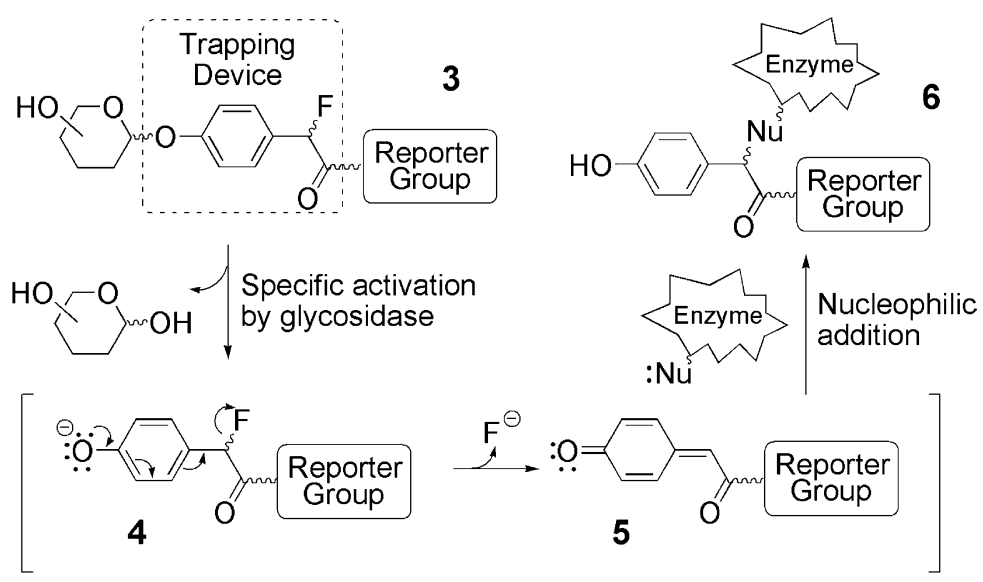

Scheme 1. General design of an activity probe 3 for GHs and the mechanism for the selective labeling event.

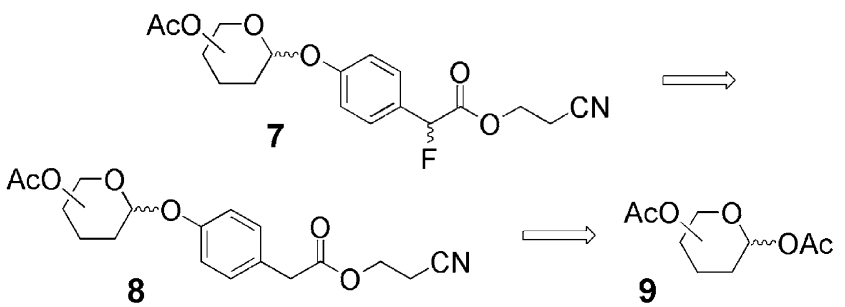

Scheme 2. Retrosynthetic pathway for the construction of building block library 7.

tions had to be prepared prior to the synthesis. Since the recognition head carries only a monosaccharide, and both anomeric products are desired in this study, we chose the shortest possible synthetic route, beginning with the easily accessible peracetylated sugars 9. Two different glycosidation conditions, each in favor of one type of anomer, were employed. $\mathrm{BF}_{3}$-mediated conditions gave mainly the 1,2-cis products, whereas the classical Koenigs-Knorr method led to the 1,2-trans products. ${ }^{23,28}$ The desired glycosidation products could be obtained after chromatographic purifications. The peracetylated glycosyl bromides needed for the latter method could be derived from the peracetylated sugars 9. The benzylic functionalization was achieved at the second stage in three steps: bromination, hydrolysis, and fluorination, to give compounds $\mathbf{7} \mathbf{a}-\mathbf{f}$ as the building block library.

\subsection{Synthesis of glycosidation products 8}

The library synthesis begins with $p$-hydroxyphenylacetic acid 10, from which the latent trapping device was derived. The design of this latent trapping device has been utilized in many biochemical applications that required covalent labeling of target proteins. ${ }^{16,21,22,29,30}$ In the previous synthesis of probe $\mathbf{1}$, the critical glycosidation step was achieved by Koenigs-Knorr method using the benzyl ester of compound $\mathbf{1 0}$ and the glucosyl bromide peracetate in the presence of AgOTf. ${ }^{16}$ However, the benzyl ester had to be removed and converted to the $\beta$-cyanoethyl ester before the introduction of the benzylic functionality. In this study, we have improved on the procedure by carrying out the glycosidation directly with $\beta$-cyanoethyl ester 11, which was obtained in $65 \%$ yield by treating acid 10 with $\beta$-cyanoethyl alcohol in the presence of concentrated $\mathrm{H}_{2} \mathrm{SO}_{4}$ catalyst (Scheme 3). Ester 11 was then subjected to two different glycosidation conditions; $\mathrm{BF}_{3}$-mediated glycosidation and Koenigs-Knorr method. In the former series, ester 11 reacted with peracetylated sugar donors 9 in the presence of $\mathrm{BF}_{3}$ to give compounds $\mathbf{8 a}-\mathbf{c}$ in $37 \%, 31 \%$, and $40 \%$ yields, respectively. Coupling constants of $3.6 \mathrm{~Hz}$ between $\mathrm{H}-1$ and $\mathrm{H}-2$ of the sugar moiety in this series of products supported the 1,2-cis configuration. For the 1,2-trans products, the corresponding peracetates 9 were first converted to peracetylated glycosyl bromides 12 by treatment with $\mathrm{HBr}-\mathrm{HOAc},{ }^{31-33}$ followed by coupling with $\beta$-cyanoethyl ester 11 under Koenigs-Knorr conditions with the assistance of AgOTf to give compounds 8d-f in $40 \%, 32 \%$, and $63 \%$ yields, respectively. Although the yields for both glycosidation reactions were only moderate, the results are reasonably acceptable due to the simplicity in the operations. The 1,2trans stereochemistry for $\mathbf{8 d}$ and $\mathbf{8 e}$ was established by the coupling constants of $7.4-7.9 \mathrm{~Hz}$ between $\mathrm{H}-1$ and $\mathrm{H}-2$. The anomeric configuration of compound $\mathbf{8 f}$ was established by the chemical shift of the anomeric proton $(5.40 \mathrm{ppm})$ and the anomeric carbon (95.4 ppm), both in support of the $\alpha$-D-configuration.

\subsection{Synthesis of building block library 7a-f}

Glycosidation products 8a-f were then subjected to benzylic functionalization (Scheme 4). Benzylic bromination was achieved by treatment with NBS and AIBN under irradiation to give benzylic bromides 13a-f in high yields $(73-95 \%)$. These benzylic bromides underwent 

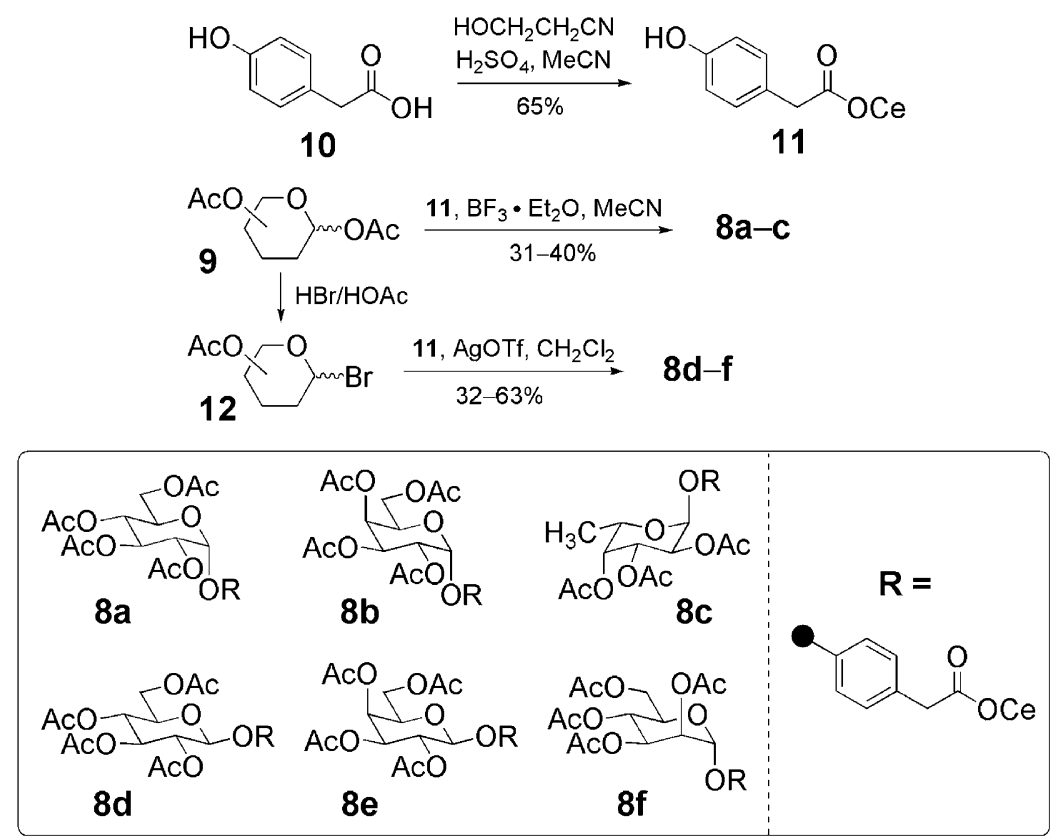

Scheme 3. The structure of compounds 8a-f and two glycosidation conditions for their formation.
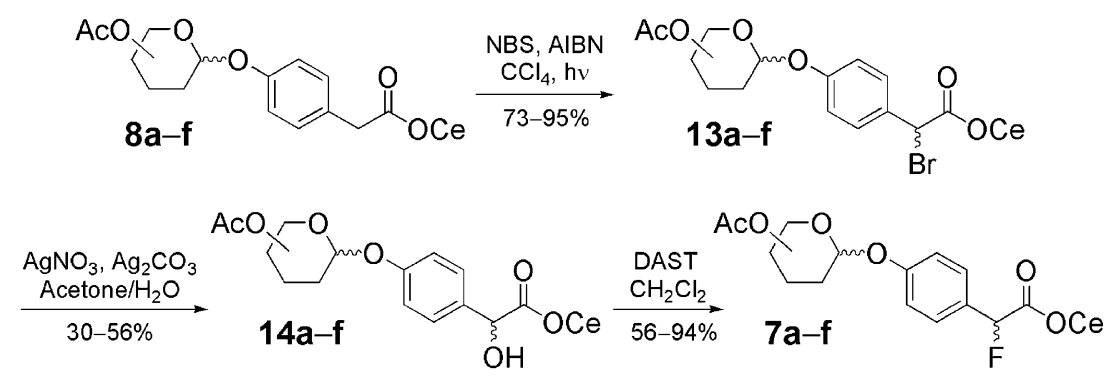

Scheme 4. Benzylic functionalization of compounds $8 \mathbf{a}-\mathbf{f}$ for the syntheses of building blocks $7 \mathbf{a}-\mathbf{f}$.

hydrolysis with $\mathrm{AgNO}_{3}$ and $\mathrm{Ag}_{2} \mathrm{CO}_{3}$ in acetone $-\mathrm{H}_{2} \mathrm{O}$ to afford benzylic alcohols 14a-f. Although the reactions were sluggish, moderate yields were obtained (30$56 \%$ ). The hydroxyl group of $\mathbf{1 4 a - f}$ was smoothly converted to fluoride by reaction with DAST to give the final products 7a-f $(56-94 \%)$. It must be noted that all the compounds prepared after benzylic functionalization are present as diastereomeric pairs. However, the newly generated stereocenter has a negligible effect on the NMR spectra, giving rise to mainly only one set of signals for each diastereomeric pair.

\subsection{Synthesis of probes $18 a-c$}

The sugar moiety and the carboxylate of building blocks $7 \mathbf{a}-\mathbf{f}$ are orthogonally protected; the former is peracetylated and the latter is protected as its $\beta$-cyanoethyl ester. For future applications, the $\beta$-cyanoethyl group of compounds 7 could be selectively removed under alkaline conditions to release carboxylic acid to which a suitable reporter group is attached through amide bond forma- tion. Here we utilize three members of the above library 7 that possess 1,2-cis configuration to prepare the GH probes 18a-c to target $\alpha$-D-glucosidase, $\alpha$-D-galactosidase, and $\alpha$-L-fucosidase, respectively (Scheme 5). Compounds $7 \mathbf{a}-\mathbf{c}$ were treated with $\mathrm{DBU}$ in $\mathrm{CH}_{2} \mathrm{Cl}_{2}$ to give $\alpha$-fluorocarboxylates 15a-c in excellent yields (94$100 \%$ ). Due to the instability of the free acids, they were isolated and stored as their triethylammonium salts. $\alpha$ Fluorocarboxylates 15a-c were coupled with a biotin derivative $16^{34}$ carrying a disulfide bridge by EDCIHOBt method to give fully protected probes $17 \mathbf{a}-\mathbf{c}$ in $65 \%, 65 \%$, and $67 \%$ yields, respectively. Compounds 17a-c were eventually subjected to deacetylation by treatment with $\mathrm{Na}_{2} \mathrm{CO}_{3}-\mathrm{MeOH}$ to give probes $18 \mathbf{a}-\mathbf{c}$. A cleavable disulfide linker is incorporated in the probes 18a-c. This cleavable linker would enable us to recover the labeled targets by treatment of a reducing agent such as DTT.

In summary, we have adopted a cassette-like design for the systematic preparation of a versatile building block library targeting GH families. An improved syn- 


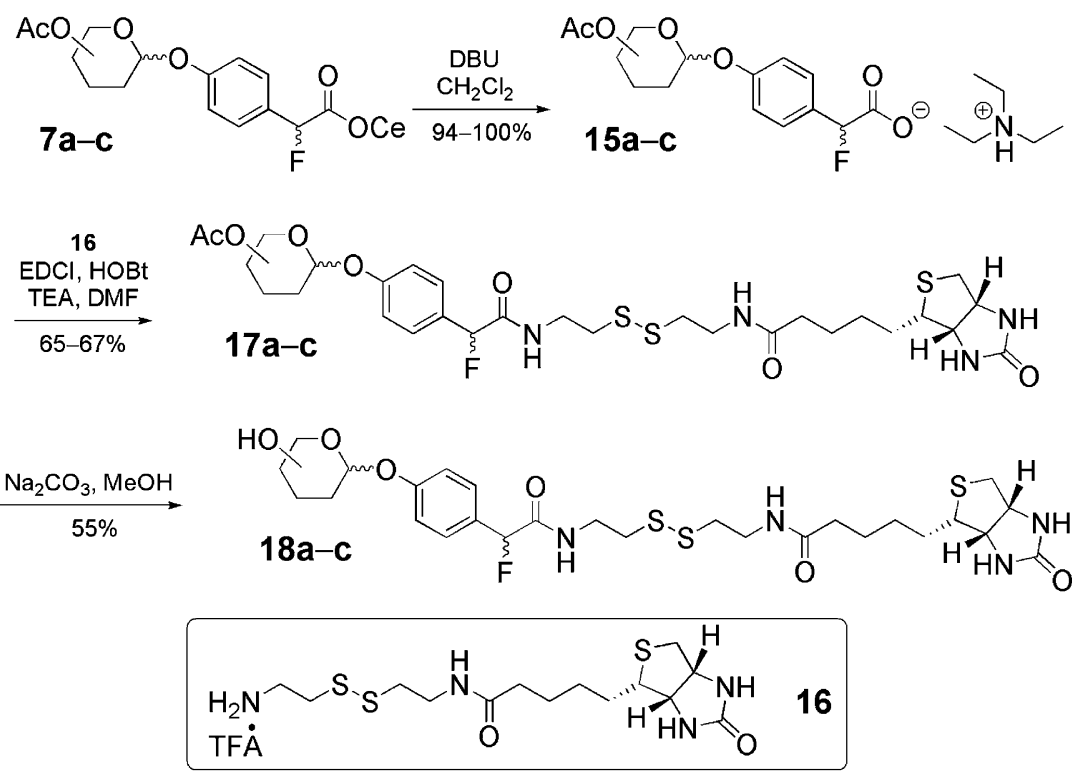

Scheme 5. The synthesis of probes 18a-c.

thetic route beginning with (4-hydroxyphenyl)-acetic acid 2-cyano-ethyl ester was developed. It could react with the designated glycosyl donors under two different coupling conditions to preferentially afford the $\alpha$ and $\beta$ anomers, respectively. Parallel syntheses were performed, and a series of sugars including $\alpha$ - and $\beta$-D-Glc, $\alpha$ - and $\beta$-D-Gal, $\alpha$-D-Man, and $\alpha$-L-Fuc were attached as the recognition head. The synthetic route presented here offers an efficient means to rapidly assemble the building block library in a straightforward manner. These versatile intermediates are the key building blocks in constructing activity probes for $\mathrm{GH}$ families and have numerous potential applications. As an example, in this study we have further utilized the building block library and demonstrated the preparation of three activity probes that have the 1,2-cis configuration, which have never been reported before. These three probes will be used for the screening of $\alpha$-D-glucosidase, $\alpha$-D-galactosidase, and $\alpha$-L-fucosidase from various biological sources.

\section{Experimental}

\subsection{General methods}

All reagents and starting materials were obtained from commercial suppliers (Acros, Aldrich and E. Merck) and were used without further purification. ${ }^{1} \mathrm{H}$ and ${ }^{13} \mathrm{C}$ NMR were recorded using a Brucker AC-300 or Bruker Avance 400 spectrometer. The proton and carbon chemical shifts are given in ppm using $\mathrm{CDCl}_{3}\left(\delta_{\mathrm{H}}\right.$ 7.24 and 77.0) as internal standard. High-resolution mass spectra were recorded with a JEOL-102A mass spectrometer. Analytical TLC (silica gel, 60F-54, E. Merck) and spots were visualized under UV light and/ or phosphomolybdic acid-EtOH. Column chromatography was performed with Kiesegel 60 (70-230 mesh) silica gel (E. Merck). Melting points are reported without correction.

\subsection{Preparation of $\beta$-cyanoethyl ester 11}

To a solution of 4-hydroxyphenylacetic acid (10.0 g, $65.8 \mathrm{mmol}), \beta$-cyanoethanol $(4.71 \mathrm{~g}, 65.8 \mathrm{mmol})$, and $10.0 \mathrm{~g}$ of anhyd $\mathrm{Na}_{2} \mathrm{SO}_{4}$ in $50 \mathrm{~mL}$ of anhyd $\mathrm{MeCN}$ was added $1.75 \mathrm{~mL}$ of concentrated $\mathrm{H}_{2} \mathrm{SO}_{4}(32.9 \mathrm{mmol})$ as a catalyst. The reaction mixture was heated under reflux for $16 \mathrm{~h}$. The solvent was removed under reduced pressure, and the residual oil was dissolved in $100 \mathrm{~mL}$ of EtOAc. The EtOAc solution was washed consecutively with satd $\mathrm{NaHCO}_{3}(\times 3), \mathrm{H}_{2} \mathrm{O}$ and brine, followed by drying over anhyd $\mathrm{Na}_{2} \mathrm{SO}_{4}$. It was filtered and concentrated to give $\beta$-cyanoethyl ester $11(8.91 \mathrm{~g})$ in $66 \%$ yield. $R_{\mathrm{f}} 0.50$ (4:1 $\mathrm{CHCl}_{3}-$ EtOAc). ${ }^{1} \mathrm{H} \mathrm{NMR}\left(\mathrm{CDCl}_{3}\right.$, $400 \mathrm{MHz}): \delta 7.10(\mathrm{~d}, J 6.5 \mathrm{~Hz}, 2 \mathrm{H}$, aromatic), 6.74 $(\mathrm{d}, J 6.5 \mathrm{~Hz}, 2 \mathrm{H}$, aromatic), $5.94($ br s, $1 \mathrm{H}), 4.25(\mathrm{t}$, $J 6.2 \mathrm{~Hz}, 2 \mathrm{H}$ ), 3.57 (s, 2H, benzylic), 2.66 (t, $J 6.2 \mathrm{~Hz}$, $2 \mathrm{H}) ;{ }^{13} \mathrm{C} \mathrm{NMR}\left(\mathrm{CDCl}_{3}, 100 \mathrm{MHz}\right): \delta 171.7(\mathrm{C}), 155.1$ (C), $130.5(\mathrm{CH}), 125.0(\mathrm{C}), 116.7(\mathrm{C}), 115.6(\mathrm{CH}), 59.0$ $\left(\mathrm{CH}_{2}\right), 40.0\left(\mathrm{CH}_{2}\right), 17.9\left(\mathrm{CH}_{2}\right)$. FABMS: $m / z(\%) 205$ $\left(\mathrm{M}^{+}, 8\right), 136$ (100); HRMS: calcd for $\mathrm{C}_{11} \mathrm{H}_{11} \mathrm{NO}_{3}$ $\left(\mathrm{M}^{+}\right)$, 205.0739; found, 205.0741.

\subsection{General procedure for the preparation of glycosidation products $8 \mathbf{a}-\mathbf{c}$}

To a solution of $\beta$-cyanoethyl ester $11(1.40 \mathrm{mmol})$ and the corresponding sugar peracetate $9(1.02 \mathrm{mmol})$ in anhyd $\mathrm{MeCN}$ was slowly added $\mathrm{BF}_{3}$.etherate $(2.25 \mathrm{mmol})$. The reaction mixture was kept at room 
temperature for $24 \mathrm{~h}$ and quenched by adding $2.25 \mathrm{mmol}$ of $\mathrm{Et}_{3} \mathrm{~N}$. The solvent was removed under reduced pressure, and the residual oil was subjected to silica gel column chromatography. The desired glycosidation products 8a-c were eluted with 1:1 hexaneEtOAc and were obtained in $31-40 \%$ yields.

3.3.1. [(4-Tetra- $O$-acetyl- $\alpha$-D-glucopyranosyloxy)phenyl]acetic acid 2-cyanoethyl ester (8a). Yield 37\% (oil), $R_{\mathrm{f}}$ $0.20 \quad\left(1: 1 \quad n\right.$-hexane-EtOAc). ${ }^{1} \mathrm{H}$ NMR $\left(\mathrm{CDCl}_{3}\right.$, $400 \mathrm{MHz}): \delta 7.16(\mathrm{~d}, J 8.6 \mathrm{~Hz}, 2 \mathrm{H}$, aromatic), $7.00(\mathrm{~d}$, $J 8.6 \mathrm{~Hz}, 2 \mathrm{H}$, aromatic), $5.65(\mathrm{~d}, J 3.6 \mathrm{~Hz}, 1 \mathrm{H}, \mathrm{H}-1)$, $5.62(\mathrm{dd}, J 10.2,9.6 \mathrm{~Hz}, 1 \mathrm{H}, \mathrm{H}-3), 5.09(\mathrm{dd}, J 10.0$, $9.6 \mathrm{~Hz}, 1 \mathrm{H}, \mathrm{H}-4), 4.97$ (dd, $J 10.2,3.6 \mathrm{~Hz}, 1 \mathrm{H}, \mathrm{H}-2$ ), $4.23(\mathrm{t}, J 6.2 \mathrm{~Hz}, 2 \mathrm{H}), 4.19(\mathrm{dd}, J 12.3,4.4 \mathrm{~Hz}, 1 \mathrm{H}, \mathrm{H}-$ 6), $4.03(\mathrm{~m}, 1 \mathrm{H}, \mathrm{H}-5), 3.98$ (dd, $J 12.3,1.9 \mathrm{~Hz}, 1 \mathrm{H}, \mathrm{H}-$ $\left.6^{\prime}\right), 3.57(\mathrm{~s}, 2 \mathrm{H}), 2.64(\mathrm{t}, J 6.2 \mathrm{~Hz}, 2 \mathrm{H}), 2.01(\mathrm{~s}, 3 \mathrm{H}$, OAc), $1.99(\mathrm{~s}, 3 \mathrm{H}, \mathrm{OAc}), 1.99(\mathrm{~s}, 3 \mathrm{H}, \mathrm{OAc}), 1.97(\mathrm{~s}$, $3 \mathrm{H}, \mathrm{OAc}) ;{ }^{13} \mathrm{C} \mathrm{NMR}\left(\mathrm{CDCl}_{3}, 100 \mathrm{MHz}\right): \delta 170.9(\mathrm{C})$, 170.3 (C), 170.0 (C), 170.0 (C), 169.4 (C), 155.2 (C), $130.3(\mathrm{CH}), 127.7(\mathrm{C}), 116.6(\mathrm{CH}), 115.3(\mathrm{C}), 94.1$ $(\mathrm{CH}), 70.2(\mathrm{CH}), 69.8(\mathrm{CH}), 68.1(\mathrm{CH}), 67.8(\mathrm{CH})$, $61.4\left(\mathrm{CH}_{2}\right), 58.9\left(\mathrm{CH}_{2}\right), 39.8\left(\mathrm{CH}_{2}\right), 20.6\left(\mathrm{CH}_{3}\right), 20.5$ $\left(\mathrm{CH}_{3}\right), 20.5\left(\mathrm{CH}_{3}\right), 20.4\left(\mathrm{CH}_{3}\right), 17.8\left(\mathrm{CH}_{2}\right)$. IR (neat): 1759, 1514, 1375, 1222, 1162, $1043 \mathrm{~cm}^{-1}$. FABMS: $m / z$ (\%) $558\left(\mathrm{M}+\mathrm{Na}^{+}, 4\right), 536\left(\mathrm{M}+1^{+}, 12\right), 331$ (100); HRMS: calcd for $\mathrm{C}_{25} \mathrm{H}_{30} \mathrm{NO}_{12}(\mathrm{M}+1)^{+}, 536.1768$; found, 536.1762 .

3.3.2. [(4-Tetra- $O$-acetyl- $\alpha$-D-galactopyranosyloxy)phenyl]acetic acid 2-cyanoethyl ester (8b). Yield 31\% (oil), $R_{\mathrm{f}}$ $0.40 \quad\left(4: 6 \quad n\right.$-hexane-EtOAc). ${ }^{1} \mathrm{H} \quad \mathrm{NMR} \quad\left(\mathrm{CDCl}_{3}\right.$, $400 \mathrm{MHz}): \delta 7.18(\mathrm{~d}, J 8.5 \mathrm{~Hz}, 2 \mathrm{H}$, aromatic), $6.99(\mathrm{~d}$, $J 8.5 \mathrm{~Hz}, 2 \mathrm{H}$, aromatic), $5.71(\mathrm{~d}, J 3.6 \mathrm{~Hz}, 1 \mathrm{H}, \mathrm{H}-1)$, $5.52(\mathrm{dd}, J 10.7,3.4 \mathrm{~Hz}, 1 \mathrm{H}, \mathrm{H}-3), 5.48(\mathrm{~m}, 1 \mathrm{H}, \mathrm{H}-4)$, $5.23(\mathrm{dd}, J 10.7,3.6 \mathrm{~Hz}, 1 \mathrm{H}, \mathrm{H}-2), 4.30(\mathrm{dd}, J 6.5$, $6.7 \mathrm{~Hz}, 1 \mathrm{H}, \mathrm{H}-5), 4.25$ (t, J $6.3 \mathrm{~Hz}, 2 \mathrm{H}), 4.10-3.99$ (m, $\left.2 \mathrm{H}, \mathrm{H}-6+\mathrm{H}-6^{\prime}\right), 3.59$ (s, 2H, benzylic), 2.66 (t, $J$ $6.3 \mathrm{~Hz}, 2 \mathrm{H}$ ), 2.12 (s, 3H, OAc), 2.03 (s, 3H, OAc), 1.98 (s, 3H, OAc), $1.91(\mathrm{~s}, 3 \mathrm{H}, \mathrm{OAc}) ;{ }^{13} \mathrm{C} \mathrm{NMR}\left(\mathrm{CDCl}_{3}\right.$, $100 \mathrm{MHz}$ ): $\delta 170.7$ (C), 170.0 (C), 169.9 (C), 169.8 (C), 169.6 (C), $155.3(\mathrm{C}), 130.2(\mathrm{CH}), 127.6(\mathrm{C}), 116.7$ $(\mathrm{CH}), 116.5(\mathrm{C}), 94.7(\mathrm{CH}), 67.5(\mathrm{CH}), 67.4(\mathrm{CH}), 67.2$ $(\mathrm{CH}), 66.8(\mathrm{CH}), 61.1\left(\mathrm{CH}_{2}\right), 58.8\left(\mathrm{CH}_{2}\right), 39.6\left(\mathrm{CH}_{2}\right)$, $20.6\left(\mathrm{CH}_{3}\right), 20.3\left(\mathrm{CH}_{3}\right), 20.2\left(\mathrm{CH}_{3}\right), 20.2\left(\mathrm{CH}_{3}\right), 17.5$ $\left(\mathrm{CH}_{2}\right)$. IR (neat): $2939,2369,1753,1514,1428,1375$, 1222, 1156, $1063 \mathrm{~cm}^{-1}$. FABMS: $m / z(\%) 536\left(\mathrm{M}+1^{+}\right.$, 7), 331 (100); HRMS: calcd for $\mathrm{C}_{25} \mathrm{H}_{30} \mathrm{NO}_{12}(\mathrm{M}+1)^{+}$, 536.1768; found, 536.1766 .

3.3.3. [(4-Tri- $O$-acetyl- $\alpha$-L-fucopyranosyloxy)phenyl]acetic acid 2-cyanoethyl ester (8c). Yield $40 \%$ (oil), $R_{\mathrm{f}} 0.37$ (8:2 $\left.\mathrm{CHCl}_{3}-\mathrm{EtOAc}\right) .{ }^{1} \mathrm{H}$ NMR $\left(\mathrm{CDCl}_{3}, 400 \mathrm{MHz}\right): \delta$ 7.19 (d, $J 8.6 \mathrm{~Hz}, 2 \mathrm{H}$, aromatic), $7.00(\mathrm{~d}, J 8.6 \mathrm{~Hz}, 2 \mathrm{H}$, aromatic), 5.69 (d, $J 3.6 \mathrm{~Hz}, 1 \mathrm{H}, \mathrm{H}-1), 5.54(\mathrm{dd}, J$ 10.9, $3.3 \mathrm{~Hz}, 1 \mathrm{H}, \mathrm{H}-3), 5.33$ (d, J $3.3 \mathrm{~Hz}, 1 \mathrm{H}, \mathrm{H}-4)$, $5.24(\mathrm{dd}, J 10.9,3.6 \mathrm{~Hz}, 1 \mathrm{H}, \mathrm{H}-2), 4.27(\mathrm{t}, J 6.3 \mathrm{~Hz}$, $2 \mathrm{H}$ ), 4.24 (q, $J 6.5 \mathrm{~Hz}, 1 \mathrm{H}, \mathrm{H}-5), 3.60$ (s, 2H, benzylic), $2.68(\mathrm{t}, J 6.3 \mathrm{~Hz}, 2 \mathrm{H}), 2.16$ (s, 3H, OAc), 2.03 (s, 3H, OAc), 1.99 (s, 3H, OAc), 1.09 (d, J $6.5 \mathrm{~Hz}, 3 \mathrm{H}, \mathrm{CH}_{3}$ ); ${ }^{13} \mathrm{C}$ NMR $\left(\mathrm{CDCl}_{3}, 100 \mathrm{MHz}\right): \delta 171.1(\mathrm{C}), 170.5(\mathrm{C})$, $170.4(\mathrm{C}), 170.0(\mathrm{C}), 155.8(\mathrm{C}), 130.5(\mathrm{CH}), 127.3(\mathrm{C})$, $116.6(\mathrm{CH}), 116.6(\mathrm{C}), 94.8(\mathrm{CH}), 70.9(\mathrm{CH}), 67.9$ $(\mathrm{CH}), 67.7(\mathrm{CH}), 65.4(\mathrm{CH}), 59.0\left(\mathrm{CH}_{2}\right), 40.0\left(\mathrm{CH}_{2}\right)$, $20.7\left(\mathrm{CH}_{3}\right), 20.7\left(\mathrm{CH}_{3}\right), 20.6\left(\mathrm{CH}_{3}\right), 17.9\left(\mathrm{CH}_{2}\right), 15.8$ $\left(\mathrm{CH}_{3}\right)$. IR (neat): 1746, 1520, 1381, 1222, 1156, $1076 \mathrm{~cm}^{-1}$. FABMS: $\mathrm{m} / \mathrm{z}(\%) 478\left(\mathrm{M}+1^{+}, 4\right), 273$ (100); HRMS: calcd for $\mathrm{C}_{23} \mathrm{H}_{28} \mathrm{NO}_{10}(\mathrm{M}+1)^{+}$, 478.1714; found, 478.1716 .

\subsection{General procedure for the preparation of glycosidation products $8 d-f$}

To an ice-cooled solution of the corresponding sugar peracetates $9(10.25 \mathrm{mmol})$ in $5 \mathrm{~mL}$ of anhyd $\mathrm{CH}_{2} \mathrm{Cl}_{2}$ was slowly added $10 \mathrm{~mL}$ of $\mathrm{HBr}-\mathrm{HOAc}$. The reaction mixture was stirred for $15 \mathrm{~min}$, and then it was poured into $100 \mathrm{~mL}$ of ice water. A white cloudy precipitate was observed. It was extracted with $100 \mathrm{~mL}$ of $\mathrm{CHCl}_{3}$. The organic layer was collected and washed with ice water $(100 \mathrm{~mL} \times 3)$, satd $\mathrm{NaHCO}_{3}(50 \mathrm{~mL} \times 2)$, and brine. The organic layer was separated and dried over anhyd $\mathrm{Na}_{2} \mathrm{SO}_{4}$. It was filtered and concentrated to give the corresponding glycosyl bromides 12, which were used without further purification. To an ice-cooled solution of $\beta$-cyanoethyl ester $\mathbf{1 1}(7.0 \mathrm{mmol})$ and AgOTf ( $6.9 \mathrm{mmol}$ ) in $20 \mathrm{~mL}$ of anhyd $\mathrm{CH}_{2} \mathrm{Cl}_{2}$ was slowly added a solution of glcosyl bromide $12(5.4 \mathrm{mmol})$ in $10 \mathrm{~mL}$ of $\mathrm{CH}_{2} \mathrm{Cl}_{2}$. The reaction mixture was kept in the dark and stirred for $2.5 \mathrm{~h}$. It was quenched by adding $3 \mathrm{~mL}$ of DIEA, followed by filtration. The filtrate was then concentrated under reduced pressure, and the residual oil was subjected to silica gel column chromatography. The desired glycosidation products $8 \mathbf{8}-\mathbf{f}$ were obtained in $32-63 \%$ by using the same conditions described above for the products $\mathbf{8 a}-\mathbf{c}$.

3.4.1. [(4-Tetra- $O$-acetyl- $\beta$-D-glucopyranosyloxy)phenyl]acetic acid 2-cyanoethyl ester (8d). Yield $40 \%$ (oil), $R_{\mathrm{f}}$ $0.25 \quad\left(8: 2 \mathrm{CHCl}_{3}-\right.$ EtOAc). ${ }^{1} \mathrm{H}$ NMR $\left(\mathrm{CDCl}_{3}\right.$, $400 \mathrm{MHz}): \delta 7.15(\mathrm{~d}, J 8.6 \mathrm{~Hz}, 2 \mathrm{H}$, aromatic), $6.89(\mathrm{~d}$, $J 8.6 \mathrm{~Hz}, 2 \mathrm{H}$, aromatic), $5.23(\mathrm{dd}, J 9.8,9.4 \mathrm{~Hz}, 1 \mathrm{H})$, $5.18(\mathrm{dd}, J 9.4,7.4 \mathrm{~Hz}, 1 \mathrm{H}), 5.09(\mathrm{dd}, J 9.8,9.2 \mathrm{~Hz}$, $1 \mathrm{H}), 5.02(\mathrm{~d}, J 7.4 \mathrm{~Hz}, 1 \mathrm{H}, \mathrm{H}-1), 4.24-4.00(\mathrm{~m}, 3 \mathrm{H})$, 4.09 (dd, $J$ 12.3, $2.2 \mathrm{~Hz}, 1 \mathrm{H}, \mathrm{H}-6), 3.81$ (m, 1H, H-5), $3.56(\mathrm{~s}, 2 \mathrm{H}$, benzylic), $2.63(\mathrm{t}, J 6.2 \mathrm{~Hz}, 2 \mathrm{H}), 2.00(\mathrm{~s}$, $3 \mathrm{H}, \mathrm{OAc}$ ), 1.98 (s, 3H, OAc), 1.97 (s, 3H, OAc), 1.97 (s, 3H, OAc); ${ }^{13} \mathrm{C}$ NMR $\left(\mathrm{CDCl}_{3}, 100 \mathrm{MHz}\right): \delta 170.9$ (C), 170.3 (C), 170.0 (C), 169.2 (C), 169.1 (C), 155.9 (C), $130.3(\mathrm{CH}), 128.0(\mathrm{C}), 116.9(\mathrm{CH}), 116.7(\mathrm{C}), 98.8$ $(\mathrm{CH}), 72.4(\mathrm{CH}), 71.7(\mathrm{CH}), 70.8(\mathrm{CH}), 68.0(\mathrm{CH})$, $61.7\left(\mathrm{CH}_{2}\right), 58.9\left(\mathrm{CH}_{2}\right), 39.8\left(\mathrm{CH}_{2}\right), 20.5\left(\mathrm{CH}_{3}\right), 20.4$ 
$\left(\mathrm{CH}_{3}\right), 20.4\left(\mathrm{CH}_{3}\right), 20.4\left(\mathrm{CH}_{3}\right), 17.7\left(\mathrm{CH}_{2}\right)$. IR (neat): 1752, 1514, 1381, 1229, 1149, $1043 \mathrm{~cm}^{-1}$. FABMS: $m / z$ (\%) $558\left(\mathrm{M}+\mathrm{Na}^{+}, 1\right), 536\left(\mathrm{M}+1^{+}, 2\right), 331$ (100); HRMS: calcd for $\mathrm{C}_{25} \mathrm{H}_{30} \mathrm{NO}_{12}(\mathrm{M}+1)^{+}$, 536.1768; found, 536.1772 .

\subsection{2. [(4-Tetra- $O$-acetyl- $\beta$-D-galactopyranosyloxy)phenyl]-} acetic acid 2-cyanoethyl ester (8e). Yield 32\% (oil), $R_{\mathrm{f}}$ $0.25 \quad\left(8: 2 \mathrm{CHCl}_{3}-\mathrm{EtOAc}\right) .{ }^{1} \mathrm{H} \quad \mathrm{NMR} \quad\left(\mathrm{CDCl}_{3}\right.$, $400 \mathrm{MHz}): \delta 7.15(\mathrm{~d}, J 8.5 \mathrm{~Hz}, 2 \mathrm{H}$, aromatic), $6.91(\mathrm{~d}$, $J 8.5 \mathrm{~Hz}, 2 \mathrm{H}$, aromatic), 5.42-5.38 (m, 2H), 5.05 (dd, $J$ 7.0, 3.4 Hz, 1H, H-3), 4.98 (d, J 7.9 Hz, 1H, H-1), 4.21 $(\mathrm{t}, J 6.2 \mathrm{~Hz}, 2 \mathrm{H}), 4.16(\mathrm{dd}, J 11.2,7.1 \mathrm{~Hz}, 1 \mathrm{H}, \mathrm{H}-6)$, $4.09\left(\mathrm{dd}, J 11.2,6.0 \mathrm{~Hz}, 1 \mathrm{H}, \mathrm{H}-6^{\prime}\right), 4.02(\mathrm{dd}, J$ 7.1, $6.0 \mathrm{~Hz}, 1 \mathrm{H}, \mathrm{H}-5), 3.57(\mathrm{~s}, 2 \mathrm{H}), 2.63$ (t, J 6.2 Hz, 2H), $2.10(\mathrm{~s}, 3 \mathrm{H}, \mathrm{OAc}), 2.00(\mathrm{~s}, 3 \mathrm{H}, \mathrm{OAc}), 1.99(\mathrm{~s}, 3 \mathrm{H}$, OAc), $1.94(\mathrm{~s}, 3 \mathrm{H}, \quad \mathrm{OAc}) ;{ }^{13} \mathrm{C}$ NMR $\left(\mathrm{CDCl}_{3}\right.$, $100 \mathrm{MHz}$ ): $\delta 170.9(\mathrm{C}), 170.2$ (C), $170.1(\mathrm{C}), 169.9(\mathrm{C})$, $169.2(\mathrm{C}), 156.0(\mathrm{C}), 130.3(\mathrm{CH}), 127.9(\mathrm{C}), 116.8$ $(\mathrm{CH}), 116.6(\mathrm{C}), 99.3(\mathrm{CH}), 70.8(\mathrm{CH}), 70.6(\mathrm{CH}), 68.4$ $(\mathrm{CH}), 66.7(\mathrm{CH}), 61.2\left(\mathrm{CH}_{2}\right), 58.9\left(\mathrm{CH}_{2}\right), 39.8\left(\mathrm{CH}_{2}\right)$, $20.5\left(\mathrm{CH}_{3}\right), 20.5\left(\mathrm{CH}_{3}\right), 20.4\left(\mathrm{CH}_{3}\right), 20.4\left(\mathrm{CH}_{3}\right), 17.7$ $\left(\mathrm{CH}_{2}\right)$. IR (neat): $1752,1235,1076 \mathrm{~cm}^{-1}$. FABMS: $\mathrm{m} / z$ (\%) $536\left(\mathrm{M}+1^{+}, 3\right), 331$ (100); HRMS: calcd for $\mathrm{C}_{25} \mathrm{H}_{30} \mathrm{NO}_{12}(\mathrm{M}+1)^{+}$, 536.1768; found, 536.1773.

3.4.3. [(4-Tetra- $O$-acetyl- $\alpha$-D-mannopyranosyloxy)phenyl]acetic acid 2-cyanoethyl ester (8f). Yield 63\% (oil), $R_{\mathrm{f}}$ $0.20 \quad\left(1: 1 \quad n\right.$-hexane-EtOAc). ${ }^{1} \mathrm{H} \quad \mathrm{NMR} \quad\left(\mathrm{CDCl}_{3}\right.$, $400 \mathrm{MHz}): \delta 7.11(\mathrm{~d}, J 8.5 \mathrm{~Hz}, 2 \mathrm{H}$, aromatic), $6.94(\mathrm{~d}$, $J 8.5 \mathrm{~Hz}, 2 \mathrm{H}$, aromatic), 5.43-5.40 (m, 2H, H-1+H-3), 5.27 (br, 1H, H-2), 5.24 (dd, J 10.0, 9.9 Hz, 1H, H-4), 4.18-4.14 (m, 3H), 3.99-3.93 (m, 2H, H-5+H-6), 3.51 (s, 2H, benzylic), $2.59(\mathrm{t}, J 6.3 \mathrm{~Hz}, 2 \mathrm{H}), 2.59(\mathrm{~s}, 3 \mathrm{H}$, OAc), 2.08 (s, 3H, OAc), 1.94 (s, 3H, OAc), 1.91 (s, $3 \mathrm{H}, \mathrm{OAc}), 1.91$ (s, 3H, OAc); ${ }^{13} \mathrm{C} \mathrm{NMR}\left(\mathrm{CDCl}_{3}\right.$, $100 \mathrm{MHz}$ ): $\delta 170.6(\mathrm{C}), 170.1$ (C), 169.5 (C), $169.5(\mathrm{C})$, $169.3(\mathrm{C}), 154.5(\mathrm{C}), 130.2(\mathrm{CH}), 127.6(\mathrm{C}), 116.6(\mathrm{C})$, $116.3(\mathrm{CH}), 95.4(\mathrm{CH}), 68.9(\mathrm{CH}), 68.7(\mathrm{CH}), 68.5$ $(\mathrm{CH}), 65.4(\mathrm{CH}), 61.7\left(\mathrm{CH}_{2}\right), 58.8\left(\mathrm{CH}_{2}\right), 39.6\left(\mathrm{CH}_{2}\right)$, $20.5\left(\mathrm{CH}_{3}\right), 20.3\left(\mathrm{CH}_{3}\right), 20.3\left(\mathrm{CH}_{3}\right), 20.3\left(\mathrm{CH}_{3}\right), 17.6$ $\left(\mathrm{CH}_{2}\right)$. IR (neat): $1745,1374,1222,1129,1043 \mathrm{~cm}^{-1}$. FABMS: $m / z(\%) 536\left(\mathrm{M}+1^{+}, 8\right), 331$ (100); HRMS: calcd for $\mathrm{C}_{25} \mathrm{H}_{30} \mathrm{NO}_{12}(\mathrm{M}+1)^{+}, \quad 536.1768$; found, 536.1770

\subsection{General procedure for the preparation of benzylic bromides 13a-f}

To a solution of compound $8(1.70 \mathrm{mmol})$ in $20 \mathrm{~mL}$ of $\mathrm{CCl}_{4}$ were added NBS $(1.90 \mathrm{mmol})$ and a catalytic amount of AIBN. The reaction flask was equipped with a condenser, and the apparatus was purged and filled with $\mathrm{N}_{2}$ three times. It was irradiated with a $100-\mathrm{W}$ tungsten lamp for $1 \mathrm{~h}$ until a white precipitate formed. The precipitate was filtered off and the filtrate was con- centrated. It was subjected to silica gel column chromatography, eluting with $15: 85 \mathrm{EtOAc}-\mathrm{CHCl}_{3}$ to give the bromides 13a-f (73-95\%) as white foams.

3.5.1. [(4-Tetra- $O$-acetyl- $\alpha$-D-glucopyranosyloxy)phenyl]bromoacetic acid 2-cyanoethyl ester (13a). Yield 85\% (oil), $R_{\mathrm{f}} 0.52$ (7:3 $\mathrm{CHCl}_{3}$-EtOAc). ${ }^{1} \mathrm{H} \mathrm{NMR}\left(\mathrm{CDCl}_{3}\right.$, $400 \mathrm{MHz}): \delta 7.46(\mathrm{~d}, J 8.6 \mathrm{~Hz}, 2 \mathrm{H}$, aromatic), $7.04(\mathrm{~d}$, $J 8.6 \mathrm{~Hz}, 2 \mathrm{H}$, aromatic), 5.69 (d, J $3.6 \mathrm{~Hz}, 1 \mathrm{H}, \mathrm{H}-1)$, 5.61 (dd, J 10.3, $9.8 \mathrm{~Hz}, 1 \mathrm{H}, \mathrm{H}-3), 5.32$ (s, 1H), 5.09 (dd, $J$ 10.7, $9.8 \mathrm{~Hz}, 1 \mathrm{H}, \mathrm{H}-4), 4.98$ (dd, $J 10.3,3.6 \mathrm{~Hz}$, $1 \mathrm{H}, \mathrm{H}-2), 4.32$ (t, $J 6.2 \mathrm{~Hz}, 2 \mathrm{H}), 4.17$ (dd, $J$ 12.6, $4.2 \mathrm{~Hz}, 1 \mathrm{H}, \mathrm{H}-6), 4.03-3.96$ (m, 2H, H-5+H-6'), 2.69 (t, J 6.2 Hz, 2H), 1.99 (s, 3H, OAc), 1.99 (s, 3H, OAc), 1.97 (s, 3H, OAc), 1.97 (s, 3H, OAc); ${ }^{13} \mathrm{C} \mathrm{NMR}\left(\mathrm{CDCl}_{3}\right.$, $100 \mathrm{MHz}$ ): $\delta 170.3(\mathrm{C}), 169.9(\mathrm{C}), 169.9$ (C), $169.4(\mathrm{C})$, 167.6 (C), 156.6 (C), $130.1(\mathrm{CH}), 129.3$ (C), 116.7 $(\mathrm{CH}), 116.2(\mathrm{C}), 93.8(\mathrm{CH}), 70.1(\mathrm{CH}), 69.7(\mathrm{CH}), 68.0$ $(\mathrm{CH}), 68.0(\mathrm{CH}), 61.3\left(\mathrm{CH}_{2}\right), 60.2\left(\mathrm{CH}_{2}\right), 44.9(\mathrm{CH})$, $20.5\left(\mathrm{CH}_{3}\right), 20.5\left(\mathrm{CH}_{3}\right), 20.4\left(\mathrm{CH}_{3}\right), 20.4\left(\mathrm{CH}_{3}\right), 17.6$ $\left(\mathrm{CH}_{2}\right)$. IR (neat): $1759,1514,1375,1235,1042 \mathrm{~cm}^{-1}$. FABMS: $m / z(\%) 616\left(\mathrm{M}+1^{+},{ }^{81} \mathrm{Br}, 60\right), 614\left(\mathrm{M}+1^{+}\right.$, $\left.{ }^{79} \mathrm{Br}, 69\right), 391$ (100); HRMS: calcd for $\mathrm{C}_{25} \mathrm{H}_{29}{ }^{79} \mathrm{BrNO}_{12}$ $(\mathrm{M}+1)^{+}$614.0873, found, 614.0872.

3.5.2. [(4-Tetra- $O$-acetyl- $\alpha$-D-galactopyranosyloxy)phenyl|bromoacetic acid 2-cyanoethyl ester (13b). Yield 87\% (oil), $R_{\mathrm{f}} 0.45$ (7:3 $\left.\mathrm{CHCl}_{3}-\mathrm{EtOAc}\right) .{ }^{1} \mathrm{H} \mathrm{NMR}\left(\mathrm{CDCl}_{3}\right.$, $400 \mathrm{MHz}$ ): $\delta 7.48$ (d, $J 8.5 \mathrm{~Hz}, 2 \mathrm{H}$, aromatic), $7.04(\mathrm{~d}$, $J 8.5 \mathrm{~Hz}, 2 \mathrm{H}$, aromatic), $5.76(\mathrm{~d}, J 3.6 \mathrm{~Hz}, 1 \mathrm{H}, \mathrm{H}-1)$, 5.52 (dd, J 10.7, 3.3 Hz, 1H, H-3), 5.48 (m, 1H, H-4), 5.33 (s, 1H), 5.24 (dd, J 10.7, 3.6 Hz, 1H, H-2), 4.30 $(\mathrm{t}, J 6.3 \mathrm{~Hz}, 2 \mathrm{H}), 4.26(\mathrm{dd}, J 7.1,5.8 \mathrm{~Hz}, 1 \mathrm{H}, \mathrm{H}-5)$, $4.08(\mathrm{dd}, J 11.2,5.8 \mathrm{~Hz}, 1 \mathrm{H}, \mathrm{H}-6), 4.02$ (dd, $J$ 11.2, $\left.7.1 \mathrm{~Hz}, 1 \mathrm{H}, \mathrm{H}-6^{\prime}\right), 2.70(\mathrm{t}, J 6.3 \mathrm{~Hz}, 2 \mathrm{H}), 2.13$ (s, 3H, OAc), 2.03 (s, 3H, OAc), 1.99 (s, 3H, OAc), $1.90(\mathrm{~s}$, $3 \mathrm{H}, \mathrm{OAc}) ;{ }^{13} \mathrm{C} \mathrm{NMR}\left(\mathrm{CDCl}_{3}, 100 \mathrm{MHz}\right): \delta 170.3(\mathrm{C})$, 170.2 (C), 170.1 (C), 169.9 (C), 167.7 (C), 156.9 (C), $130.2(\mathrm{CH}), 129.3(\mathrm{C}), 116.9(\mathrm{CH}), 116.2(\mathrm{C}), 94.6$ $(\mathrm{CH}), 67.6(\mathrm{CH}), 67.5(\mathrm{CH}), 67.3(\mathrm{CH}), 67.2(\mathrm{CH})$, $61.2\left(\mathrm{CH}_{2}\right), 60.3\left(\mathrm{CH}_{2}\right), 45.0(\mathrm{CH}), 20.6\left(\mathrm{CH}_{3}\right), 20.5$ $\left(\mathrm{CH}_{3}\right), 20.5\left(\mathrm{CH}_{3}\right), 20.5\left(\mathrm{CH}_{3}\right), 17.7\left(\mathrm{CH}_{2}\right)$. IR (neat): 1745, 1520, 1374, 1228, 1175, 1129, $1063 \mathrm{~cm}^{-1}$. FABMS: $m / z(\%) 616\left(\mathrm{M}+1^{+},{ }^{81} \mathrm{Br}, 11\right), 614\left(\mathrm{M}+1^{+},{ }^{79} \mathrm{Br}, 10\right)$, 391 (100); HRMS: calcd for $\mathrm{C}_{25} \mathrm{H}_{29}{ }^{79} \mathrm{BrNO}_{12}(\mathrm{M}+1)^{+}$, 614.0873; found, 614.0878.

3.5.3. [(4-Tri- $O$-acetyl- $\alpha$-L-fucopyranosyloxy)phenyl]bromoacetic acid 2-cyanoethyl ester (13c). Yield 83\% (oil), $R_{\mathrm{f}} 0.45$ (85:15 $\left.\mathrm{CHCl}_{3}-\mathrm{EtOAc}\right) .{ }^{1} \mathrm{H} \mathrm{NMR} \quad\left(\mathrm{CDCl}_{3}\right.$, $400 \mathrm{MHz}): \delta 7.48$ (d, $J 8.8 \mathrm{~Hz}, 2 \mathrm{H}$, aromatic), 7.04 (d, $J 8.8 \mathrm{~Hz}, 2 \mathrm{H}$, aromatic), $5.72(\mathrm{~d}, J 3.6 \mathrm{~Hz}, 1 \mathrm{H}, \mathrm{H}-1)$, $5.53(\mathrm{dd}, J 10.9,3.3 \mathrm{~Hz}, 1 \mathrm{H}, \mathrm{H}-3), 5.33-5.32(\mathrm{~m}, 2 \mathrm{H})$, 5.24 (dd, J 10.9, 3.6 Hz, 1H, H-2), 4.38-4.33 (m, 2H), 4.20 (q, J 6.7 Hz, 1H, H-5), 2.72 (t, J 6.3 Hz, 2H), 2.16 (s, 3H, OAc), 2.03 (s, 3H, OAc), 2.00 (s, 3H, OAc), 
$1.09\left(\mathrm{~d}, J 6.7 \mathrm{~Hz}, 3 \mathrm{H}, \mathrm{CH}_{3}\right) ;{ }^{13} \mathrm{C} \mathrm{NMR}\left(\mathrm{CDCl}_{3}\right.$, $100 \mathrm{MHz}$ ): $\delta 170.5(\mathrm{C}), 170.4(\mathrm{C}), 170.1(\mathrm{C}), 167.8(\mathrm{C})$, $157.4(\mathrm{C}), 130.3(\mathrm{CH}), 128.9(\mathrm{C}), 116.7(\mathrm{CH}), 116.2$ $(\mathrm{C}), 94.6(\mathrm{CH}), 70.8(\mathrm{CH}), 67.8(\mathrm{CH}), 67.6(\mathrm{CH}), 65.6$ $(\mathrm{CH}), 60.3\left(\mathrm{CH}_{2}\right), 45.1(\mathrm{CH}), 20.7\left(\mathrm{CH}_{3}\right), 20.7\left(\mathrm{CH}_{3}\right)$, $20.6\left(\mathrm{CH}_{3}\right), 17.7\left(\mathrm{CH}_{2}\right), 15.8\left(\mathrm{CH}_{3}\right)$. IR (neat): 1746, 1520, 1375, 1228, 1175, 1129, $1070 \mathrm{~cm}^{-1}$. FABMS: $\mathrm{m} / z$ (\%) $558\left(\mathrm{M}+1^{+},{ }^{81} \mathrm{Br}, 1\right), 556\left(\mathrm{M}+1^{+},{ }^{79} \mathrm{Br}, 0.9\right), 273$ (100).

3.5.4. [(4-Tetra- $O$-acetyl- $\beta$-D-glucopyranosyloxy)phenyl]bromoacetic acid 2-cyanoethyl ester (13d). Yield $88 \%$ (oil), $R_{\mathrm{f}} 0.38$ (8:2 $\left.\mathrm{CHCl}_{3}-\mathrm{EtOAc}\right) .{ }^{1} \mathrm{H}$ NMR $\left(\mathrm{CDCl}_{3}\right.$, $400 \mathrm{MHz}): \delta 7.48(\mathrm{~d}, J 8.6 \mathrm{~Hz}, 2 \mathrm{H}$, aromatic), $6.96(\mathrm{~d}$, $J 8.6 \mathrm{~Hz}, 2 \mathrm{H}$, aromatic), $5.33(\mathrm{~s}, 1 \mathrm{H}), 5.30-5.21(\mathrm{~m}$, $2 \mathrm{H}), 5.15(\mathrm{~m}, 1 \mathrm{H}), 5.09(\mathrm{~d}, J 7.2 \mathrm{~Hz}, 1 \mathrm{H}, \mathrm{H}-1), 4.40$ $4.31(\mathrm{~m}, 2 \mathrm{H}), 4.25(\mathrm{dd}, J 12.3,5.2 \mathrm{~Hz}, 1 \mathrm{H}, \mathrm{H}-6), 4.14$ (dd, $\left.J 12.3,2.3 \mathrm{~Hz}, 1 \mathrm{H}, \mathrm{H}-6^{\prime}\right), 3.86(\mathrm{~m}, 1 \mathrm{H}, \mathrm{H}-5), 2.71$ (t, $J 6.3 \mathrm{~Hz}, 2 \mathrm{H}), 2.05$ (s, 3H, OAc), 2.02 (s, 3H, OAc), 2.01 (s, 3H, OAc), 1.99 (s, 3H, OAc); ${ }^{13} \mathrm{C} \mathrm{NMR}\left(\mathrm{CDCl}_{3}\right.$, $100 \mathrm{MHz}): \delta 170.5(\mathrm{C}), 170.2(\mathrm{C}), 169.3(\mathrm{C}), 169.2(\mathrm{C})$, 167.8 (C), $157.4(\mathrm{C}), 130.2(\mathrm{CH}), 129.7(\mathrm{C}), 117.1$ $(\mathrm{CH}), 116.2(\mathrm{C}), 98.5(\mathrm{CH}), 72.5(\mathrm{CH}), 72.1(\mathrm{CH}), 71.0$ $(\mathrm{CH}), 68.1(\mathrm{CH}), 61.8\left(\mathrm{CH}_{2}\right), 60.3\left(\mathrm{CH}_{2}\right), 45.0(\mathrm{CH})$, $20.7\left(\mathrm{CH}_{3}\right), 20.7\left(\mathrm{CH}_{3}\right), 20.6\left(\mathrm{CH}_{3}\right), 20.6\left(\mathrm{CH}_{3}\right), 17.7$ $\left(\mathrm{CH}_{2}\right)$. IR (neat): $1759,1388,1229,1043 \mathrm{~cm}^{-1}$. FABMS: $\mathrm{m} / \mathrm{z}(\%) 638\left(\mathrm{M}+\mathrm{Na}^{+},{ }^{81} \mathrm{Br}, 79\right), 636\left(\mathrm{M}+\mathrm{Na}^{+},{ }^{79} \mathrm{Br}\right.$, 83), $616\left(\mathrm{M}+1^{+},{ }^{81} \mathrm{Br}, 79\right), 614\left(\mathrm{M}+1^{+},{ }^{79} \mathrm{Br}, 100\right), 391$ (96); HRMS: calcd for $\mathrm{C}_{25} \mathrm{H}_{29}{ }^{79} \mathrm{BrNO}_{12}(\mathrm{M}+1)^{+}$, 614.0873; found, 614.0872.

3.5.5. [(4-Tetra- $O$-acetyl- $\beta$-D-galactopyranosyloxy)phenyl]bromoacetic acid 2-cyanoethyl ester (13e). Yield 73\% (oil), $R_{\mathrm{f}} 0.32$ (8:2 $\mathrm{CHCl}_{3}$-EtOAc). ${ }^{1} \mathrm{H}$ NMR $\left(\mathrm{CDCl}_{3}\right.$, $400 \mathrm{MHz}$ ): $\delta 7.48$ (d, $J 8.7 \mathrm{~Hz}, 2 \mathrm{H}$, aromatic), 6.97 (d, $J 8.7 \mathrm{~Hz}, 2 \mathrm{H}$, aromatic), $5.47-5.42(\mathrm{~m}, 2 \mathrm{H}), 5.33(\mathrm{~s}$, $1 \mathrm{H}), 5.08(\mathrm{dd}, J 7.0,3.4 \mathrm{~Hz}, 1 \mathrm{H}), 5.04(\mathrm{~d}, J 7.9 \mathrm{~Hz}$, $1 \mathrm{H}, \mathrm{H}-1), 4.40-4.24(\mathrm{~m}, 2 \mathrm{H}), 4.18(\mathrm{dd}, J 11.3,7.1 \mathrm{~Hz}$, 1H, H-6), 4.12 (dd, J 12.3, 6.0 Hz, 1H, H-6'), 4.05 (dd, $J$ 7.1, $6.0 \mathrm{~Hz}, 1 \mathrm{H}, \mathrm{H}-5), 2.72-2.65(\mathrm{~m}, 2 \mathrm{H}), 2.14$ (s, $3 \mathrm{H}, \mathrm{OAc}), 2.02$ (s, 3H, OAc), 2.00 (s, 3H, OAc) 1.98 (s, 3H, OAc); ${ }^{13} \mathrm{C} \mathrm{NMR}\left(\mathrm{CDCl}_{3}, 100 \mathrm{MHz}\right): \delta 170.3$ (C), 170.1 (C), 170.0 (C), 169.3 (C), 167.8 (C), 157.5 (C), $130.2(\mathrm{CH}), 129.6(\mathrm{C}), 117.1(\mathrm{CH}), 116.1(\mathrm{C}), 99.1$ $(\mathrm{CH}), 71.1(\mathrm{CH}), 70.7(\mathrm{CH}), 68.4(\mathrm{CH}), 66.8(\mathrm{CH})$, $61.3\left(\mathrm{CH}_{2}\right), 60.3\left(\mathrm{CH}_{2}\right), 45.0(\mathrm{CH}), 20.7\left(\mathrm{CH}_{3}\right), 20.6$ $\left(\mathrm{CH}_{3}\right), 20.6\left(\mathrm{CH}_{3}\right), 20.5\left(\mathrm{CH}_{3}\right), 17.7\left(\mathrm{CH}_{2}\right)$. IR (neat): 1746, $1235, \quad 1076 \mathrm{~cm}^{-1}$. FABMS: $\mathrm{m} / \mathrm{z}(\%) 638$ $\left(\mathrm{M}+\mathrm{Na}^{+},{ }^{81} \mathrm{Br}, 79\right), 636\left(\mathrm{M}+\mathrm{Na}^{+},{ }^{79} \mathrm{Br}, 83\right), 616$ $\left(\mathrm{M}+1^{+},{ }^{81} \mathrm{Br}, 1\right), 614\left(\mathrm{M}+1^{+},{ }^{79} \mathrm{Br}, 1\right), 331$ (100); HRMS: calcd for $\mathrm{C}_{25} \mathrm{H}_{29}{ }^{79} \mathrm{BrNO}_{12}(\mathrm{M}+1)^{+}, 614.0873$; found, 614.0878 .

3.5.6. [(4-Tetra- $O$-acetyl- $\alpha$-D-mannopyranosyloxy)phenyl]bromoacetic acid 2-cyanoethyl ester (13f). Yield 95\% (oil), $R_{\mathrm{f}} 0.55$ (1:1 $\mathrm{CHCl}_{3}$-EtOAc). ${ }^{1} \mathrm{H}$ NMR $\left(\mathrm{CDCl}_{3}\right.$,
$400 \mathrm{MHz}): \delta 7.45$ (d, $J 8.7 \mathrm{~Hz}, 2 \mathrm{H}$, aromatic), 7.03 (d, $J 8.7 \mathrm{~Hz}, 2 \mathrm{H}$, aromatic), $5.48(\mathrm{~d}, J 1.6 \mathrm{~Hz}, 1 \mathrm{H}, \mathrm{H}-1)$, $5.46(\mathrm{dd}, J 10.1,3.5 \mathrm{~Hz}, 1 \mathrm{H}, \mathrm{H}-3), 5.36(\mathrm{dd}, J 3.5$, $1.6 \mathrm{~Hz}, 1 \mathrm{H}, \mathrm{H}-2), 5.31(\mathrm{br}, 1 \mathrm{H}), 5.25(\mathrm{dd}, J 10.1$, $10.0 \mathrm{~Hz}, 1 \mathrm{H}, \mathrm{H}-4), 4.33-4.28(\mathrm{~m}, 2 \mathrm{H}), 4.20(\mathrm{dd}, J$ 12.1, 6.2 Hz, 1H, H-6), 4.01-3.98 (m, 2H, H-5+H-6'), $2.68(\mathrm{t}, J 6.3 \mathrm{~Hz}, 2 \mathrm{H}), 2.13$ (s, 3H, OAc), 1.99 (s, 3H, OAc), 1.97 (s, 3H, OAc), 1.96 (s, 3H, OAc); ${ }^{13} \mathrm{C}$ NMR $\left(\mathrm{CDCl}_{3}, 100 \mathrm{MHz}\right): \delta 170.5(\mathrm{C}), 169.9(\mathrm{C}), 169.7(\mathrm{C})$, $167.8(\mathrm{C}), 167.8(\mathrm{C}), 156.2(\mathrm{C}), 130.2(\mathrm{CH}), 129.5(\mathrm{C})$, $116.8(\mathrm{CH}), 116.3(\mathrm{C}), 95.6(\mathrm{CH}), 69.2(\mathrm{CH}), 69.1$ $(\mathrm{CH}), 68.7(\mathrm{CH}), 65.7(\mathrm{CH}), 62.0\left(\mathrm{CH}_{2}\right), 60.4\left(\mathrm{CH}_{2}\right)$, $45.1(\mathrm{CH}), 20.8\left(\mathrm{CH}_{3}\right), 20.8\left(\mathrm{CH}_{3}\right), 20.7\left(\mathrm{CH}_{3}\right), 20.7$ $\left(\mathrm{CH}_{3}\right), 17.7\left(\mathrm{CH}_{2}\right)$. IR (neat): 1759, 1507, 1374, 1228, 1135, $1043 \mathrm{~cm}^{-1}$. FABMS: $m / z(\%) 616\left(\mathrm{M}+1^{+}\right.$, $\left.{ }^{81} \mathrm{Br}, 5\right), 614\left(\mathrm{M}+1^{+},{ }^{79} \mathrm{Br}, 5\right), 331$ (100); HRMS: calcd for $\mathrm{C}_{25} \mathrm{H}_{29}{ }^{79} \mathrm{BrNO}_{12} \quad(\mathrm{M}+1)^{+}, \quad 614.0873$; found, 614.0876 .

\subsection{General procedure for the preparation of benzylic alcohols 14a-f}

Benzylic bromide $13(1.50 \mathrm{mmol})$ was dissolved in $5 \mathrm{~mL}$ of acetone. A solution of $\mathrm{AgNO}_{3}(3.00 \mathrm{mmol})$ and $\mathrm{Ag}_{2} \mathrm{CO}_{3}(0.75 \mathrm{mmol})$ in $5 \mathrm{~mL}$ of $\mathrm{H}_{2} \mathrm{O}$ was added. A dark greenish precipitate formed immediately. The reaction mixture was stirred in the dark at $\mathrm{rt}$ for $30 \mathrm{~min}$. It was filtered and the filtrate was concentrated to dryness. The residual oil was dissolved in EtOAc and washed with $5 \%$ citric acid $(\times 3)$, satd $\mathrm{NaHCO}_{3}(\times 3)$ and brine. The organic phase was dried over anhyd $\mathrm{Na}_{2} \mathrm{SO}_{4}$, filtered, and concentrated. The resulting oil was chromatographed on silica gel (4:6 EtOAc- $\left.\mathrm{CHCl}_{3}\right)$ to give benzylic alcohols 14a-f in $30-56 \%$ yields.

3.6.1. [(4-Tetra- $O$-acetyl- $\alpha$-D-glucopyranosyloxy)phenyl]hydroxyacetic acid 2-cyanoethyl ester (14a). Yield 38\% (oil), $R_{\mathrm{f}} 0.25$ (1:1 $\left.\mathrm{CHCl}_{3}-\mathrm{EtOAc}\right) .{ }^{1} \mathrm{H}$ NMR $\left(\mathrm{CDCl}_{3}\right.$, $400 \mathrm{MHz}): \delta 7.32$ (d, $J 8.6 \mathrm{~Hz}, 2 \mathrm{H}$, aromatic), $7.03(\mathrm{~d}$, $J 8.6 \mathrm{~Hz}, 2 \mathrm{H}$, aromatic), $5.67(\mathrm{~d}, J 3.6 \mathrm{~Hz}, 1 \mathrm{H}, \mathrm{H}-1)$, $5.62(\mathrm{dd}, J 10.2,9.6 \mathrm{~Hz}, 1 \mathrm{H}, \mathrm{H}-3), 5.15(\mathrm{~d}, J 5.6 \mathrm{~Hz}$, $1 \mathrm{H}), 5.10(\mathrm{dd}, J 10.0,9.6 \mathrm{~Hz}, 1 \mathrm{H}, \mathrm{H}-4), 4.97(\mathrm{dd}, J$ $10.2,3.6 \mathrm{~Hz}, 1 \mathrm{H}, \mathrm{H}-2), 4.32(\mathrm{~m}, 1 \mathrm{H}), 4.21(\mathrm{~m}, 1 \mathrm{H})$, 4.17 (dd, $J 12.9,4.2 \mathrm{~Hz}, 1 \mathrm{H}, \mathrm{H}-6), 4.05-3.96(\mathrm{~m}, 2 \mathrm{H}$, $\mathrm{H}-5+\mathrm{H}-6), 3.58(\mathrm{~d}, J 5.6 \mathrm{~Hz}, 1 \mathrm{H}, \mathrm{OH}), 2.63(\mathrm{~m}, 2 \mathrm{H})$, $1.99(\mathrm{~s}, 3 \mathrm{H}, \mathrm{OAc}), 1.99(\mathrm{~s}, 3 \mathrm{H}, \mathrm{OAc}), 1.97(\mathrm{~s}, 3 \mathrm{H}$, OAc), $1.97(\mathrm{~s}, \quad 3 \mathrm{H}, \quad \mathrm{OAc}) ;{ }^{13} \mathrm{C} \quad \mathrm{NMR} \quad\left(\mathrm{CDCl}_{3}\right.$, $100 \mathrm{MHz}): \delta 172.8(\mathrm{C}), 170.4(\mathrm{C}), 170.1(\mathrm{C}), 170.0(\mathrm{C})$, $169.5(\mathrm{C}), 156.1(\mathrm{C}), 132.2(\mathrm{C}), 127.9(\mathrm{CH}), 116.7$ $(\mathrm{CH}), 116.2(\mathrm{C}), 94.0(\mathrm{CH}), 72.1(\mathrm{CH}), 70.2(\mathrm{CH}), 69.8$ $(\mathrm{CH}), 68.0(\mathrm{CH}), 67.8(\mathrm{CH}), 61.4\left(\mathrm{CH}_{2}\right), 59.8\left(\mathrm{CH}_{2}\right)$, $20.5\left(\mathrm{CH}_{3}\right), 20.5\left(\mathrm{CH}_{3}\right), 20.5\left(\mathrm{CH}_{3}\right), 20.4\left(\mathrm{CH}_{3}\right), 17.7$ $\left(\mathrm{CH}_{2}\right)$. IR (neat): 3489, 1752, 1507, 1374, 1228, $1043 \mathrm{~cm}^{-1}$. FABMS: $m / z(\%) 552\left(\mathrm{M}+1^{+}, 5\right), 331$ (100); HRMS: calcd for $\mathrm{C}_{25} \mathrm{H}_{30} \mathrm{NO}_{13}(\mathrm{M}+1)^{+}$, 552.1714; found, 552.1721. 
3.6.2. [(4-Tetra- $O$-acetyl- $\alpha$-D-galactopyranosyloxy)phenyl]hydroxyacetic acid 2-cyanoethyl ester (14b). Yield 45\% (oil), $R_{\mathrm{f}} 0.30$ (1:1 $\mathrm{CHCl}_{3}-$ EtOAc). ${ }^{1} \mathrm{H}$ NMR $\left(\mathrm{CDCl}_{3}\right.$, $400 \mathrm{MHz}): \delta 7.31$ (d, $J 8.7 \mathrm{~Hz}, 2 \mathrm{H}$, aromatic), $6.99(\mathrm{~d}$, $J 8.7 \mathrm{~Hz}, 2 \mathrm{H}$, aromatic), $5.69(\mathrm{~d}, J 3.2 \mathrm{~Hz}, 1 \mathrm{H}, \mathrm{H}-1)$, 5.49-5.45 (m, 2H, H-3+H-4), 5.19 (dd, $J 10.6,3.2 \mathrm{~Hz}$, $1 \mathrm{H}, \mathrm{H}-2), 5.14(\mathrm{~d}, J 5.5 \mathrm{~Hz}, 1 \mathrm{H}), 4.31-4.16(\mathrm{~m}, 3 \mathrm{H})$, 4.083-3.97 (m, 2H, H-6+H-6'), $3.33(\mathrm{~s}, 1 \mathrm{H}, \mathrm{OH})$, 2.63-2.58 (m, 2H), $2.09(\mathrm{~s}, 3 \mathrm{H}, \mathrm{OAC}), 1.99(\mathrm{~s}, 3 \mathrm{H}$, OAC), $1.94(\mathrm{~s}, 3 \mathrm{H}, \mathrm{OAC}), 1.86(\mathrm{~s}, 3 \mathrm{H}, \mathrm{OAC}) ;{ }^{13} \mathrm{C}$ NMR $\left(\mathrm{CDCl}_{3}, 100 \mathrm{MHz}\right): \delta 172.6(\mathrm{C}), 170.2(\mathrm{C})$, 170.2 (C), 170.0 (C), 169.9 (C), 156.2 (C), 132.2 (C), $127.8(\mathrm{CH}), 116.8(\mathrm{CH}), 116.3(\mathrm{C}), 94.7(\mathrm{CH}), 72.1$ $(\mathrm{CH}), 67.6(\mathrm{CH}), 67.5(\mathrm{CH}), 67.2(\mathrm{CH}), 66.9(\mathrm{CH})$, $61.2\left(\mathrm{CH}_{2}\right), 59.6\left(\mathrm{CH}_{2}\right), 20.5\left(\mathrm{CH}_{3}\right), 20.4\left(\mathrm{CH}_{3}\right), 20.4$ $\left(\mathrm{CH}_{3}\right), 20.3\left(\mathrm{CH}_{3}\right), 17.6\left(\mathrm{CH}_{2}\right)$. IR (neat): 3489, 2985 , $1752,1613,1513,1434,1374,1228,1175,1129$, $1076 \mathrm{~cm}^{-1}$. FABMS: $\mathrm{m} / z(\%) 552\left(\mathrm{M}+1^{+}, 10\right), 331$ (100); HRMS: calcd for $\mathrm{C}_{25} \mathrm{H}_{30} \mathrm{NO}_{13}(\mathrm{M}+1)^{+}$, 552.1714; found, 552.1722 .

3.6.3. [(4-Tri- $O$-acetyl- $\alpha$-L-fucopyranosyloxy)phenyl]hydroxyacetic acid 2-cyanoethyl ester (14c). Yield $30 \%$, (oil); $R_{\mathrm{f}} 0.17$ (7:3 $\left.\mathrm{CHCl}_{3}-\mathrm{EtOAc}\right) .{ }^{1} \mathrm{H}$ NMR $\left(\mathrm{CDCl}_{3}, 400 \mathrm{MHz}\right): \delta 7.33(\mathrm{~d}, J 8.7 \mathrm{~Hz}, 2 \mathrm{H}$, aromatic), $7.03(\mathrm{~d}, J 8.7 \mathrm{~Hz}, 2 \mathrm{H}$, aromatic), $5.70(\mathrm{~d}, J 3.5 \mathrm{~Hz}, 1 \mathrm{H}$, $\mathrm{H}-1), 5.53(\mathrm{dd}, J 10.9,3.4 \mathrm{~Hz}, 1 \mathrm{H}, \mathrm{H}-3), 5.32(\mathrm{~d}, J$ $3.4 \mathrm{~Hz}, 1 \mathrm{H}, \mathrm{H}-4), 5.23$ (dd, $J 10.9,3.5 \mathrm{~Hz}, 1 \mathrm{H}, \mathrm{H}-2)$, $5.18(\mathrm{~d}, J 4.2 \mathrm{~Hz}, 1 \mathrm{H}), 4.37-4.21(\mathrm{~m}, 2 \mathrm{H}), 4.30(\mathrm{q}, J$ $6.7 \mathrm{~Hz}, 1 \mathrm{H}, \mathrm{H}-5), 3.42$ (br s, $1 \mathrm{H}, \mathrm{OH}), 2.67-2.63$ (m, $2 \mathrm{H}), 2.16$ (s, 3H, OAc), 2.02 (s, 3H, OAc), 1.99 (s, 3H, $\mathrm{OAc}), 1.08\left(\mathrm{~d}, J 6.7 \mathrm{~Hz}, 3 \mathrm{H}, \mathrm{CH}_{3}\right) ;{ }^{13} \mathrm{C} \mathrm{NMR}\left(\mathrm{CDCl}_{3}\right.$, $100 \mathrm{MHz}): \delta 173.0(\mathrm{C}), 170.6(\mathrm{C}), 170.5(\mathrm{C}), 170.2(\mathrm{C})$, $156.9(\mathrm{C}), 131.9(\mathrm{C}), 128.0(\mathrm{CH}), 116.8(\mathrm{CH}), 116.2$ (C), $94.8(\mathrm{CH}), 72.4(\mathrm{CH}), 70.9(\mathrm{CH}), 67.9(\mathrm{CH})$, $67.8(\mathrm{CH}), 65.5(\mathrm{CH}), 59.9\left(\mathrm{CH}_{2}\right), 20.8\left(\mathrm{CH}_{3}\right), 20.7$ $\left(\mathrm{CH}_{3}\right), 20.7\left(\mathrm{CH}_{3}\right), 17.9\left(\mathrm{CH}_{2}\right), 15.9\left(\mathrm{CH}_{3}\right)$. IR (neat): $3483, \quad 1759,1514,1381,1229,1189,1076 \mathrm{~cm}^{-1}$. FABMS: $m / z(\%) 494\left(\mathrm{M}+1^{+}, 6\right), 273$ (100); HRMS: calcd for $\mathrm{C}_{23} \mathrm{H}_{28} \mathrm{NO}_{11}(\mathrm{M}+1)^{+}, 494.1662$; found, 494.1670.

3.6.4. [(4-Tetra- $O$-acetyl- $\beta$-D-glucopyranosyloxy)phenyl]hydroxyacetic acid 2-cyanoethyl ester (14d). Yield 56\% (oil), $R_{\mathrm{f}} 0.20$ (1:1 $\mathrm{CHCl}_{3}-$ EtOAc). ${ }^{1} \mathrm{H}$ NMR $\left(\mathrm{CDCl}_{3}\right.$, $400 \mathrm{MHz}): \delta 7.35(\mathrm{~d}, J 8.6 \mathrm{~Hz}, 2 \mathrm{H}), 6.99(\mathrm{~d}, J 8.6 \mathrm{~Hz}$, 2H), 5.30-5.21 (m, 2H), $5.19(\mathrm{~d}, J 5.6 \mathrm{~Hz}, 1 \mathrm{H}), 5.14$ (dd, $J 9.8,9.5 \mathrm{~Hz}, 1 \mathrm{H}), 5.07(\mathrm{~d}, J 7.6 \mathrm{~Hz}, 1 \mathrm{H}, \mathrm{H}-1)$, $4.38(\mathrm{~m}, 1 \mathrm{H}), 4.30-4.22(\mathrm{~m}, 2 \mathrm{H}), 4.14(\mathrm{dd}, J 12.4$, $1.9 \mathrm{~Hz}, 1 \mathrm{H}, \mathrm{H}-6), 3.84$ (m, 1H, H-5), 3.30 (d, $J 5.6 \mathrm{~Hz}$, $1 \mathrm{H}, \mathrm{OH}), 2.67-2.62(\mathrm{~m}, 2 \mathrm{H}), 2.05(\mathrm{~s}, 3 \mathrm{H}), 2.03(\mathrm{~s}, 3 \mathrm{H})$, $2.02(\mathrm{~s}, 3 \mathrm{H}), 2.01(\mathrm{~s}, 3 \mathrm{H}) ;{ }^{13} \mathrm{C}$ NMR $\left(\mathrm{CDCl}_{3}\right.$, $100 \mathrm{MHz}): \delta 172.9(\mathrm{C}), 170.6(\mathrm{C}), 170.2(\mathrm{C}), 169.4(\mathrm{C})$, $169.3(\mathrm{C}), 157.1(\mathrm{C}), 132.5(\mathrm{C}), 127.9(\mathrm{CH}), 117.2$ $(\mathrm{CH}), 117.1(\mathrm{C}), 98.9(\mathrm{CH}), 72.6(\mathrm{CH}), 72.2(\mathrm{CH}), 72.0$
$(\mathrm{CH}), 71.1(\mathrm{CH}), 68.2(\mathrm{CH}), 61.9\left(\mathrm{CH}_{2}\right), 60.0\left(\mathrm{CH}_{2}\right)$, $20.7\left(\mathrm{CH}_{3}\right), 20.6\left(\mathrm{CH}_{3}\right), 20.6\left(\mathrm{CH}_{3}\right), 20.6\left(\mathrm{CH}_{3}\right), 17.9$ $\left(\mathrm{CH}_{2}\right)$. IR (neat): 3481, 2969, 2259, 1746, 1517, 1372, 1227, 1182, $1044 \mathrm{~cm}^{-1}$. FABMS: $m / z(\%) 552\left(\mathrm{M}+1^{+}\right.$, 5), 331 (100); HRMS: calcd for $\mathrm{C}_{25} \mathrm{H}_{30} \mathrm{NO}_{13}(\mathrm{M}+1)^{+}$, 552.1714; found, 552.1721.

3.6.5. [(4-Tetra- $O$-acetyl- $\beta$-D-galactopyranosyloxy)phenyl]hydroxyacetic acid 2-cyanoethyl ester (14e). Yield 40\% (oil), $R_{\mathrm{f}} 0.25$ (1:1 $\mathrm{CHCl}_{3}$-EtOAc). ${ }^{1} \mathrm{H}$ NMR $\left(\mathrm{CDCl}_{3}\right.$, $400 \mathrm{MHz}): \delta 7.33(\mathrm{~d}, J 7.5 \mathrm{~Hz}, 2 \mathrm{H}$, aromatic), $6.96(\mathrm{~d}$, $J 8.6 \mathrm{~Hz}, 2 \mathrm{H}$, aromatic), 5.45-5.40 (m, 2H), $5.17(\mathrm{~d}, J$ $5.2 \mathrm{~Hz}, 1 \mathrm{H}), 5.07(\mathrm{dd}, J 7.0,3.4 \mathrm{~Hz}, 1 \mathrm{H}), 5.01(\mathrm{~d}, J$ $7.9 \mathrm{~Hz}, 1 \mathrm{H}, \mathrm{H}-1), 4.38-4.21(\mathrm{~m}, 2 \mathrm{H}), 4.17$ (dd, $J 11.3$, $7.1 \mathrm{~Hz}, 1 \mathrm{H}, \mathrm{H}-6), 4.11\left(\mathrm{dd}, J 11.3,6.1 \mathrm{~Hz}, 1 \mathrm{H}, \mathrm{H}-6^{\prime}\right)$, $4.03(\mathrm{dd}, J 7.1,6.1 \mathrm{~Hz}, 1 \mathrm{H}, \mathrm{H}-5), 3.47(\mathrm{~d}, J 4.8 \mathrm{~Hz}$, $1 \mathrm{H}), 2.68-2.60(\mathrm{~m}, 2 \mathrm{H}), 2.13$ (s, 3H, OAc), 2.01 (s, 3H, $\mathrm{OAc}), 2.01$ (s, 3H, OAc), 1.80 (s, 3H, OAc); ${ }^{13} \mathrm{C}$ NMR $\left(\mathrm{CDCl}_{3}, 100 \mathrm{MHz}\right): \delta 172.9(\mathrm{C}), 170.4(\mathrm{C}), 170.3(\mathrm{C})$, 170.1 (C), $169.4(\mathrm{C}), 157.1(\mathrm{C}), 132.6(\mathrm{C}), 127.9(\mathrm{CH})$, $117.1(\mathrm{CH}), 116.3(\mathrm{C}), 99.4(\mathrm{CH}), 72.3(\mathrm{CH}), 71.1$ $(\mathrm{CH}), 70.8(\mathrm{CH}), 68.6(\mathrm{CH}), 66.9(\mathrm{CH}), 61.4\left(\mathrm{CH}_{2}\right)$, $59.9\left(\mathrm{CH}_{2}\right), 20.7\left(\mathrm{CH}_{3}\right), 20.7\left(\mathrm{CH}_{3}\right), 20.6\left(\mathrm{CH}_{3}\right), 20.6$ $\left(\mathrm{CH}_{3}\right), 17.9\left(\mathrm{CH}_{2}\right)$. IR (neat): 3443, 1752, 1235, $1063 \mathrm{~cm}^{-1}$. FABMS: $m / z(\%) 552\left(\mathrm{M}+1^{+}, 6\right), 331$ (100); HRMS: calcd for $\mathrm{C}_{25} \mathrm{H}_{30} \mathrm{NO}_{13}(\mathrm{M}+1)^{+}$, 552.1714; found, 552.1721.

3.6.6. [(4-Tetra- $O$-acetyl- $\alpha$-D-mannopyranosyloxy)phenyl]hydroxyacetic acid 2-cyanoethyl ester (14f). Yield 39\% (oil), $R_{\mathrm{f}} 0.25$ (1:1 $\left.\mathrm{CHCl}_{3}-\mathrm{EtOAc}\right) .{ }^{1} \mathrm{H}$ NMR $\left(\mathrm{CDCl}_{3}\right.$, $400 \mathrm{MHz}$ ): $\delta 7.33$ (d, $J 8.7 \mathrm{~Hz}, 2 \mathrm{H}$, aromatic), $7.05(\mathrm{~d}$, $J 8.7 \mathrm{~Hz}, 2 \mathrm{H}$, aromatic), 5.51-5.48 (m, 2H, H-1+H-3), $5.38(\mathrm{dd}, J 3.4,1.7 \mathrm{~Hz}, 1 \mathrm{H}, \mathrm{H}-2), 5.32(\mathrm{dd}, J 10.1$, $10.0 \mathrm{~Hz}, 1 \mathrm{H}, \mathrm{H}-4), 5.16(\mathrm{~d}, J 5.3 \mathrm{~Hz}, 1 \mathrm{H}), 4.37-4.31$ $(\mathrm{m}, 1 \mathrm{H}), 4.27-4.20(\mathrm{~m}, 2 \mathrm{H}), 4.04-4.00(\mathrm{~m}, 2 \mathrm{H}, \mathrm{H}-$ 5+H-6 $), 3.46(\mathrm{br}, 1 \mathrm{H}, \mathrm{OH}), 2.64-2.60(\mathrm{~m}, 2 \mathrm{H}), 2.15$ (s, 3H, OAc), 2.00 (s, 3H, OAc), 1.99 (s, 3H, OAc), 1.87 (s, 3H, OAc); ${ }^{13} \mathrm{C} \mathrm{NMR}\left(\mathrm{CDCl}_{3}, 100 \mathrm{MHz}\right): \delta$ 172.8 (C), 170.5 (C), 169.7 (C), 169.6 (C), 169.6 (C), $155.8(\mathrm{C}), 132.2(\mathrm{C}), 127.9(\mathrm{CH}), 116.7(\mathrm{CH}), 116.1$ (C), $95.7(\mathrm{CH}), 72.2(\mathrm{CH}), 69.2(\mathrm{CH}), 69.1(\mathrm{CH}), 68.7$ $(\mathrm{CH}), 65.8(\mathrm{CH}), 62.0\left(\mathrm{CH}_{2}\right), 59.8\left(\mathrm{CH}_{2}\right), 20.7\left(\mathrm{CH}_{3}\right)$, $20.7\left(\mathrm{CH}_{3}\right), 20.5\left(\mathrm{CH}_{3}\right), 20.5\left(\mathrm{CH}_{3}\right), 17.7\left(\mathrm{CH}_{2}\right)$. IR (neat): $3489,1752,1513,1374,1228,1182,1043 \mathrm{~cm}^{-1}$. FABMS: $m / z(\%) 552\left(\mathrm{M}+1^{+}, 7\right), 331(100)$; HRMS: calcd for $\mathrm{C}_{25} \mathrm{H}_{30} \mathrm{NO}_{13}(\mathrm{M}+1)^{+}, 552.1714$; found, 552.1716 .

\subsection{General procedure for the preparation of fluorinated products $7 \mathbf{a}-\mathbf{f}$}

To an ice-cooled solution of compound 14 (0.67 mmol) in $10 \mathrm{~mL}$ of anhyd $\mathrm{CH}_{2} \mathrm{Cl}_{2}$ was added $213 \mu \mathrm{L}$ $(1.40 \mathrm{mmol})$ of DAST. The reaction mixture was allowed to warm to $\mathrm{rt}$, and it was stirred for $15 \mathrm{~h}$. It 
was then quenched by adding small amount of silica gel and $1.5 \mathrm{~mL}$ of $\mathrm{MeOH}$. It was concentrated and the fluorinated products $7 \mathbf{a}-\mathbf{f}$ were obtained as white foam after silica gel column chromatography, eluting with 2:8 EtOAc- $-\mathrm{CHCl}_{3}$.

3.7.1. [(4-Tetra- $O$-acetyl- $\alpha$-D-glucopyranosyloxy)phenyl]fluoroacetic acid 2-cyanoethyl ester (7a). Yield $89 \%$ (oil), $R_{\mathrm{f}} 0.37$ (7:3 $\mathrm{CHCl}_{3}$-EtOAc). ${ }^{1} \mathrm{H}$ NMR $\left(\mathrm{CDCl}_{3}\right.$, $400 \mathrm{MHz}): \delta 7.34(\mathrm{~d}, J 8.4 \mathrm{~Hz}, 2 \mathrm{H}$, aromatic), $7.06(\mathrm{~d}$, $J 8.4 \mathrm{~Hz}, 2 \mathrm{H}$, aromatic), $5.72(\mathrm{~d}, J 47.1 \mathrm{~Hz}, 1 \mathrm{H}, \mathrm{CHF})$, $5.67(\mathrm{~d}, J 3.6 \mathrm{~Hz}, 1 \mathrm{H}, \mathrm{H}-1), 5.59(\mathrm{dd}, J 10.3,9.7 \mathrm{~Hz}$, 1H, H-3), 5.07 (dd, $J 11.1,9.7 \mathrm{~Hz}, 1 \mathrm{H}, \mathrm{H}-4), 4.95$ (dd, $J 10.3,3.6 \mathrm{~Hz}, 1 \mathrm{H}, \mathrm{H}-2), 4.33-4.24(\mathrm{~m}, 2 \mathrm{H}), 4.15(\mathrm{dd}$, $J$ 12.3, 4.4 Hz, 1H, H-6), 4.01-3.93 (m, 2H, H-5+H-6), 2.56-2.61 (m, 2H), $1.96(\mathrm{~s}, 3 \mathrm{H}, \mathrm{OAc}), 1.96(\mathrm{~s}, 3 \mathrm{H}$, OAc), 1.94 (s, 3H, OAc), 1.93 (s, 3H, OAc); ${ }^{13} \mathrm{C}$ NMR $\left(\mathrm{CDCl}_{3}, 100 \mathrm{MHz}\right): \delta 170.2(\mathrm{C}), 169.9(\mathrm{C}), 169.9(\mathrm{C})$, 169.3 (C), 167.7 (d, J $29 \mathrm{~Hz}, \mathrm{C}), 156.9$ (C), 128.3 $(\mathrm{CH}), 127.9(\mathrm{~d}, J 21 \mathrm{~Hz}, \mathrm{C}), 116.7(\mathrm{CH}), 116.1(\mathrm{C})$, $93.8(\mathrm{CH}), 88.3(\mathrm{~d}, J 185 \mathrm{~Hz}, C \mathrm{HF}), 70.0(\mathrm{CH}), 69.6$ $(\mathrm{CH}), 67.9(\mathrm{CH}), 67.9(\mathrm{CH}), 61.2\left(\mathrm{CH}_{2}\right), 59.6\left(\mathrm{CH}_{2}\right)$, $20.4\left(\mathrm{CH}_{3}\right), 20.3\left(\mathrm{CH}_{3}\right), 20.3\left(\mathrm{CH}_{3}\right), 20.3\left(\mathrm{CH}_{3}\right), 17.6$ $\left(\mathrm{CH}_{2}\right)$. IR (neat): $2972,1745,1619,1520,1374,1228$, $1043 \mathrm{~cm}^{-1}$. FABMS: $\mathrm{m} / z(\%) 576\left(\mathrm{M}+\mathrm{Na}^{+}, 4\right), 554$ $\left(\mathrm{M}+1^{+}, 14\right), 331$ (100); HRMS: calcd for $\mathrm{C}_{25} \mathrm{H}_{29} \mathrm{FNO}_{12}$ $(\mathrm{M}+1)^{+}, 554.1674$; found, 554.1671.

3.7.2. [(4-Tetra- $O$-acetyl- $\alpha$-D-galactopyranosyloxy)phenyl]fluoroacetic acid 2-cyanoethyl ester (7b). Yield 94\% (oil), $R_{\mathrm{f}} 0.40$ (7:3 $\mathrm{CHCl}_{3}$-EtOAc). ${ }^{1} \mathrm{H}$ NMR $\left(\mathrm{CDCl}_{3}\right.$, $400 \mathrm{MHz}$ ): $\delta 7.37$ (d, $J 8.7 \mathrm{~Hz}, 2 \mathrm{H}$, aromatic), 7.07 (d, $J 8.7 \mathrm{~Hz}, 2 \mathrm{H}$, aromatic), $5.75(\mathrm{~d}, J 47.2 \mathrm{~Hz}, 1 \mathrm{H}, \mathrm{CHF})$, $5.75(\mathrm{~d}, J 3.6 \mathrm{~Hz}, 1 \mathrm{H}, \mathrm{H}-1), 5.48(\mathrm{dd}, J 10.7,3.4 \mathrm{~Hz}$, $1 \mathrm{H}, \mathrm{H}-3), 5.46(\mathrm{~m}, 1 \mathrm{H}, \mathrm{H}-4), 5.23(\mathrm{dd}, J 10.7,3.6 \mathrm{~Hz}$, $1 \mathrm{H}, \mathrm{H}-2), 4.36(\mathrm{~m}, 1 \mathrm{H}), 4.32-4.26(\mathrm{~m}, 2 \mathrm{H}), 4.10-4.00$ (m, 2H, H-6+H-6'), 2.69-2.65 (m, 2H), $2.11(\mathrm{~s}, 3 \mathrm{H}$, OAc), 2.01 (s, 3H, OAc), 1.97 (s, 3H, OAc), 1.88 (s, $3 \mathrm{H}, \mathrm{OAc}) ;{ }^{13} \mathrm{C} \mathrm{NMR}\left(\mathrm{CDCl}_{3}, 100 \mathrm{MHz}\right): \delta 170.2(\mathrm{C})$, 170.1 (C), 170.0 (C), 169.9 (C), 167.7 (d, $J 28 \mathrm{~Hz}, \mathrm{C})$, $157.3(\mathrm{C}), 128.4(\mathrm{CH}), 127.9(\mathrm{~d}, J 21 \mathrm{~Hz}, \mathrm{C}), 117.0$ (CH), 116.1 (C), $94.7(\mathrm{CH}), 88.3$ (d, J $190 \mathrm{~Hz}, C H F)$, $67.6(\mathrm{CH}), 67.5(\mathrm{CH}), 67.3(\mathrm{CH}), 67.2(\mathrm{CH}), 61.2$ $\left(\mathrm{CH}_{2}\right), \quad 59.6\left(\mathrm{CH}_{2}\right), 20.6\left(\mathrm{CH}_{3}\right), 20.5\left(\mathrm{CH}_{3}\right), 20.5$ $\left(\mathrm{CH}_{3}\right), 20.4\left(\mathrm{CH}_{3}\right), 17.7\left(\mathrm{CH}_{2}\right)$. IR (neat): 1752, 1606, 1513, 1374, 1235, 1189, 1129, $1069 \mathrm{~cm}^{-1}$. FABMS: $\mathrm{m} / z$ (\%) $576\left(\mathrm{M}+\mathrm{Na}^{+}, 3\right), 554\left(\mathrm{M}+1^{+}, 7\right), 331$ (100); HRMS: calcd for $\mathrm{C}_{25} \mathrm{H}_{29} \mathrm{FNO}_{12}(\mathrm{M}+1)^{+}$, 554.1674; found, 554.1678 .

3.7.3. [(4-Tri- $O$-acetyl- $\alpha$-L-fucopyranosyloxy)phenyl]fluoroacetic acid 2-cyanoethyl ester (7c). Yield 85\% (oil), $R_{\mathrm{f}}$ 0.50 (7:3 $\mathrm{CHCl}_{3}$-EtOAc). ${ }^{1} \mathrm{H}$ NMR $\left(\mathrm{CDCl}_{3}, 400 \mathrm{MHz}\right)$ : $\delta 7.35(\mathrm{~d}, J 8.5 \mathrm{~Hz}, 2 \mathrm{H}$, aromatic), $7.05(\mathrm{~d}, J 8.5 \mathrm{~Hz}, 2 \mathrm{H}$, aromatic), $5.74(\mathrm{~d}, J 47.2 \mathrm{~Hz}, 1 \mathrm{H}, \mathrm{CHF}), 5.70(\mathrm{~d}, J$
$3.6 \mathrm{~Hz}, 1 \mathrm{H}, \mathrm{H}-1), 5.49$ (dd, $J 10.9,3.3 \mathrm{~Hz}, 1 \mathrm{H}, \mathrm{H}-3$ ), $5.30(\mathrm{~d}, J 3.3 \mathrm{~Hz}, 1 \mathrm{H}, \mathrm{H}-4), 5.21(\mathrm{dd}, J 10.9,3.6 \mathrm{~Hz}$, $1 \mathrm{H}, \mathrm{H}-2), 4.38-4.26(\mathrm{~m}, 2 \mathrm{H}), 4.18(\mathrm{q}, J 6.5 \mathrm{~Hz}, 1 \mathrm{H}, \mathrm{H}-$ 5), 2.73-2.64 (m, 2H), 2.13 (s, 3H, OAc), $2.00(\mathrm{~s}, 3 \mathrm{H}$, OAc), $1.97(\mathrm{~s}, 3 \mathrm{H}, \mathrm{OAc}), 1.06\left(\mathrm{~d}, J 6.5 \mathrm{~Hz}, 3 \mathrm{H}, \mathrm{CH}_{3}\right)$; ${ }^{13} \mathrm{C}$ NMR $\left(\mathrm{CDCl}_{3}, 100 \mathrm{MHz}\right): \delta 170.4(\mathrm{C}), 170.3(\mathrm{C})$, 170.0 (C), 167.9 (d, J 29 Hz, C), 157.6 (C), 128.4 $(\mathrm{CH}), 127.5(\mathrm{~d}, J 20 \mathrm{~Hz}, \mathrm{C}), 116.7(\mathrm{CH}), 116.2(\mathrm{C})$, $94.6(\mathrm{CH}), 88.4(\mathrm{~d}, J 185 \mathrm{~Hz}, C \mathrm{HF}), 70.6(\mathrm{CH}), 67.6$ $(\mathrm{CH}), 67.5(\mathrm{CH}), 65.4(\mathrm{CH}), 59.6\left(\mathrm{CH}_{2}\right), 20.6\left(\mathrm{CH}_{3}\right)$, $20.5\left(\mathrm{CH}_{3}\right), 20.4\left(\mathrm{CH}_{3}\right), 17.7\left(\mathrm{CH}_{2}\right), 15.7\left(\mathrm{CH}_{3}\right)$. IR (neat): $1759,1613,1520,1381,1229,1076,983 \mathrm{~cm}^{-1}$. FABMS: $m / z(\%) 496\left(\mathrm{M}+1^{+}, 3\right), 273$ (100); HRMS: calcd for $\mathrm{C}_{23} \mathrm{H}_{27} \mathrm{FNO}_{10}(\mathrm{M}+1)^{+}$, 496.1619; found, 496.1617 .

3.7.4. [(4-Tetra- $O$-acetyl- $\beta$-D-glucopyranosyloxy)phenyl]fluoroacetic acid 2-cyanoethyl ester (7d). Yield 86\% (oil), $R_{\mathrm{f}} 0.38$ (7:3 $\mathrm{CHCl}_{3}$-EtOAc). ${ }^{1} \mathrm{H}$ NMR $\left(\mathrm{CDCl}_{3}\right.$, $400 \mathrm{MHz}): \delta 7.39$ (d, $J 8.4 \mathrm{~Hz}, 2 \mathrm{H}), 7.00(\mathrm{~d}, J 8.4 \mathrm{~Hz}$, $2 \mathrm{H}), 5.76(\mathrm{~d}, J 47.1 \mathrm{~Hz}, 1 \mathrm{H}, \mathrm{CHF}), 5.30-5.22(\mathrm{~m}, 2 \mathrm{H})$, $5.14(\mathrm{dd}, J 9.2,8.6 \mathrm{~Hz}, 1 \mathrm{H}), 5.09(\mathrm{~d}, J 7.6 \mathrm{~Hz}, 1 \mathrm{H}, \mathrm{H}-$ 1), $4.38(\mathrm{~m}, 1 \mathrm{H}), 4.31(\mathrm{~m}, 1 \mathrm{H}), 4.25(\mathrm{dd}, J 12.3$, $5.2 \mathrm{~Hz}, 1 \mathrm{H}, \mathrm{H}-6), 4.14$ (dd, $J 12.3,2.0 \mathrm{~Hz}, 1 \mathrm{H}, \mathrm{H}-6^{\prime}$ ), $3.85(\mathrm{~m}, 1 \mathrm{H}, \mathrm{H}-5), 2.70-2.66(\mathrm{~m}, 2 \mathrm{H}), 2.04(\mathrm{~s}, 3 \mathrm{H}$, OAc), 2.02 (s, 3H, OAc), 2.02 (s, 3H, OAc), $2.00(\mathrm{~s}$, $3 \mathrm{H}, \mathrm{OAc}) ;{ }^{13} \mathrm{C} \mathrm{NMR}\left(\mathrm{CDCl}_{3}, 100 \mathrm{MHz}\right): \delta 170.5(\mathrm{C})$, 170.1 (C), 169.3 (C), 169.2 (C), 167.9 (C), 157.8 (C), $128.4(\mathrm{CH}), 128.3(\mathrm{C}), 117.2(\mathrm{CH}), 116.1(\mathrm{C}), 98.6$ $(\mathrm{CH}), 88.5(\mathrm{~J} 185 \mathrm{~Hz}, \mathrm{CHF}), 72.5(\mathrm{CH}), 72.1(\mathrm{CH})$, $71.0(\mathrm{CH}), 68.1(\mathrm{CH}), 61.8\left(\mathrm{CH}_{2}\right), 59.7\left(\mathrm{CH}_{2}\right), 20.6$ $\left(\mathrm{CH}_{3}\right), 20.6\left(\mathrm{CH}_{3}\right), 20.5\left(\mathrm{CH}_{3}\right), 20.5\left(\mathrm{CH}_{3}\right), 17.8$ $\left(\mathrm{CH}_{2}\right)$. IR (neat): $1759,1235,1043 \mathrm{~cm}^{-1}$. FABMS: $\mathrm{m} / z$ (\%) $576\left(\mathrm{M}+\mathrm{Na}^{+}, 25\right), 554\left(\mathrm{M}+1^{+}, 100\right)$; HRMS: calcd for $\mathrm{C}_{25} \mathrm{H}_{29} \mathrm{FNO}_{12}(\mathrm{M}+1)^{+}$, 554.1674; found, 554.1678.

3.7.5. [(4-Tetra- $O$-acetyl- $\beta$-D-galactopyranosyloxy)phenyl]fluoroacetic acid 2-cyanoethyl ester (7e). Yield 52\% (oil), $R_{\mathrm{f}} 0.32$ (7:3 $\mathrm{CHCl}_{3}-$ EtOAc). ${ }^{1} \mathrm{H}$ NMR $\left(\mathrm{CDCl}_{3}\right.$, $400 \mathrm{MHz}): \delta 7.38$ (d, $J 8.4 \mathrm{~Hz}, 2 \mathrm{H}$, aromatic), 7.01 (d, $J 8.4 \mathrm{~Hz}, 2 \mathrm{H}$, aromatic), $5.76(\mathrm{~d}, J 47.2 \mathrm{~Hz}, 1 \mathrm{H}, \mathrm{CHF})$, $5.47-5.42(\mathrm{~m}, 2 \mathrm{H}), 5.08(\mathrm{dd}, J 7.0,3.4 \mathrm{~Hz}, 1 \mathrm{H}), 5.04$ $(\mathrm{d}, J 7.9 \mathrm{~Hz}, 1 \mathrm{H}, \mathrm{H}-1), 4.41-4.27(\mathrm{~m}, 2 \mathrm{H}), 4.24(\mathrm{dd}, J$ $12.1,5.2 \mathrm{~Hz}, 1 \mathrm{H}, \mathrm{H}-6), 4.13(\mathrm{dd}, J 12.1,2.1 \mathrm{~Hz}, 1 \mathrm{H}$, H-6'), $4.05(\mathrm{~m}, 1 \mathrm{H}, \mathrm{H}-5), 2.69-2.65(\mathrm{~m}, 2 \mathrm{H}), 2.14(\mathrm{~s}$, $3 \mathrm{H}, \mathrm{OAc}), 2.02$ (s, 3H, OAc), 2.02 (s, 3H, OAc), 1.97 (s, 3H, OAc); ${ }^{13} \mathrm{C} \mathrm{NMR}\left(\mathrm{CDCl}_{3}, 100 \mathrm{MHz}\right): \delta 170.3$ (C), 170.1 (C), 170.0 (C), 169.3 (C), 167.8 (C), 157.9 (C), $128.4(\mathrm{CH}), 128.2(\mathrm{C}), 117.1\left(\mathrm{CH}_{2}\right), 116.1(\mathrm{C})$, $99.1(\mathrm{CH}), 88.5(\mathrm{~d}, J 185 \mathrm{~Hz}, C \mathrm{HF}), 71.1(\mathrm{CH}), 70.6$ $(\mathrm{CH}), 68.4(\mathrm{CH}), 66.8(\mathrm{CH}), 61.3\left(\mathrm{CH}_{2}\right), 59.7\left(\mathrm{CH}_{2}\right)$, $20.6\left(\mathrm{CH}_{3}\right), 20.6\left(\mathrm{CH}_{3}\right), 20.6\left(\mathrm{CH}_{3}\right), 20.5\left(\mathrm{CH}_{3}\right), 17.8$ $\left(\mathrm{CH}_{2}\right)$. IR (neat): $1752,1514,1235,1083 \mathrm{~cm}^{-1}$. FABMS: $m / z(\%) 554\left(\mathrm{M}+1^{+}, 8\right), 331$ (100); HRMS: calcd for $\mathrm{C}_{25} \mathrm{H}_{29} \mathrm{FNO}_{12}(\mathrm{M}+1)^{+}$, 554.1674; found, 554.1685. 
3.7.6. [(4-Tetra- $O$-acetyl- $\alpha$-D-mannopyranosyloxy)phenyl]fluoroacetic acid 2-cyanoethyl ester (7f). Yield $85 \%$ (oil), $R_{\mathrm{f}} 0.37$ (7:3 $\mathrm{CHCl}_{3}-$ EtOAc). ${ }^{1} \mathrm{H}$ NMR $\left(\mathrm{CDCl}_{3}\right.$, $400 \mathrm{MHz}): \delta 7.39$ (d, $J 8.3 \mathrm{~Hz}, 2 \mathrm{H}$, aromatic), $7.11(\mathrm{~d}$, $J 8.3 \mathrm{~Hz}, 2 \mathrm{H}$, aromatic), $5.76(\mathrm{~d}, J 47.2 \mathrm{~Hz}, 1 \mathrm{H}, \mathrm{CHF})$, 5.52-5.49 (m, 2H, H-1+H-3), $5.40(\mathrm{dd}, J 3.4,1.8,1 \mathrm{H}$, $\mathrm{H}-2), 5.34(\mathrm{dd}, J 10.0,9.9 \mathrm{~Hz}, 1 \mathrm{H}, \mathrm{H}-4), 4.41-4.28(\mathrm{~m}$, $2 \mathrm{H}), 4.23(\mathrm{dd}, J 12.9,5.9 \mathrm{~Hz}, 1 \mathrm{H}, \mathrm{H}-6), 4.04-4.01$ (m, $\left.2 \mathrm{H}, \mathrm{H}-5+\mathrm{H}-6^{\prime}\right), 2.70-2.66(\mathrm{~m}, 2 \mathrm{H}), 2.16$ (s, 3H, OAc), 2.01 (s, 3H, OAc), $2.00(\mathrm{~s}, 3 \mathrm{H}, \mathrm{OAc}), 1.99(\mathrm{~s}, 3 \mathrm{H}$, $\mathrm{OAc}) ;{ }^{13} \mathrm{C}$ NMR $\left(\mathrm{CDCl}_{3}, 100 \mathrm{MHz}\right): \delta 170.4(\mathrm{C})$, 169.9 (C), 169.9 (C), 169.6 (C), 167.9 (C), 156.7 (C), $128.4(\mathrm{CH}), 128.0(\mathrm{~d}, J 21 \mathrm{~Hz}, \mathrm{C}), 116.8(\mathrm{CH}), 116.1$ (C), $95.6(\mathrm{CH}), 88.5(\mathrm{~d}, J 185 \mathrm{~Hz}, C \mathrm{HF}), 69.2(\mathrm{CH})$, $69.2(\mathrm{CH}), 68.7(\mathrm{CH}), 65.7(\mathrm{CH}), 61.9\left(\mathrm{CH}_{2}\right), 59.7$ $\left(\mathrm{CH}_{2}\right), 20.8\left(\mathrm{CH}_{3}\right), 20.6\left(\mathrm{CH}_{3}\right), 20.6\left(\mathrm{CH}_{3}\right), 20.6$ $\left(\mathrm{CH}_{3}\right), 17.8\left(\mathrm{CH}_{2}\right)$. IR (neat): 1759, 1368, 1228, 1043 $\mathrm{cm}^{-1}$. FABMS: $m / z(\%) 554\left(\mathrm{M}+1^{+}, 5\right), 331$ (100); HRMS: calcd for $\mathrm{C}_{25} \mathrm{H}_{29} \mathrm{FNO}_{12}(\mathrm{M}+1)^{+}, 554.1674$; found, 554.1667.

\subsection{General procedure for the deprotection of $\beta$-cyano- ethyl esters}

To a solution of fluoride $7(0.26 \mathrm{mmol})$ in $5 \mathrm{~mL}$ of $\mathrm{CH}_{2} \mathrm{Cl}_{2}$ was added $57 \mu \mathrm{L}(0.52 \mathrm{mmol})$ of DBU. The reaction mixture was stirred at $\mathrm{rt}$ for $30 \mathrm{~min}$. EtOAc $(20 \mathrm{~mL})$ was then added, and the organic extract was washed with $5 \%$ citric acid $(\times 3), \mathrm{H}_{2} \mathrm{O}(\times 2)$, and brine $(\times 1)$. The organic phase was collected, dried over anhyd $\mathrm{Na}_{2} \mathrm{SO}_{4}$, and filtered. Since the $\alpha$-fluoroacids were not stable, they were stored as the triethylammonium salts. This was achieved by adding $1 \mathrm{~mL}$ of TEA to the filtrate. The triethylammonium salts $\mathbf{1 5 a}-\mathbf{c}$ were obtained in high yields (94-100\%) after concentration.

3.8.1. Triethylammonium [(4-tetra- $O$-acetyl- $\alpha$-D-glucopyranosyloxy)phenyl]fluoroacetate (15a). Yield 94\% (oil), $R_{\mathrm{f}} 0.33\left(8: 2 \mathrm{CHCl}_{3}-\mathrm{MeOH}\right) .{ }^{1} \mathrm{H}$ NMR $\left(\mathrm{CDCl}_{3}\right.$, $400 \mathrm{MHz}$ ): $\delta 7.40$ (d, $J 8.4 \mathrm{~Hz}, 2 \mathrm{H}$, aromatic), 7.03 (d, $J 8.4 \mathrm{~Hz}, 2 \mathrm{H}$, aromatic), 5.69-5.65 (m, 2H, H-1+H-3), $5.58(\mathrm{~d}, J 37.4 \mathrm{~Hz}, 1 \mathrm{H}, \mathrm{C} H \mathrm{~F}), 5.11(\mathrm{dd}, J 10.1,9.5 \mathrm{~Hz}$, $1 \mathrm{H}, \mathrm{H}-4), 5.00$ (dd, $J 10.1,3.5 \mathrm{~Hz}, 1 \mathrm{H}, \mathrm{H}-2), 4.22$ (dd, $J$ 12.3, 4.2 Hz, 1H, H-6), 4.09-3.98 (m, 2H, H-5+H$\left.6^{\prime}\right), 3.04(\mathrm{q}, J 7.3 \mathrm{~Hz}, 6 \mathrm{H}, \mathrm{TEA}), 2.02$ (s, 3H, OAc), $2.02(\mathrm{~s}, 3 \mathrm{H}, \mathrm{OAc}), 2.01(\mathrm{~s}, 3 \mathrm{H}, \mathrm{OAc}), 2.01(\mathrm{~s}, 3 \mathrm{H}$, OAc), $1.21(\mathrm{t}, J 7.3 \mathrm{~Hz}, 9 \mathrm{H}, \mathrm{TEA}) ;{ }^{13} \mathrm{C} \mathrm{NMR}\left(\mathrm{CDCl}_{3}\right.$, $100 \mathrm{MHz}): \delta 173.9(\mathrm{C}), 170.6(\mathrm{C}), 170.1(\mathrm{C}), 170.1(\mathrm{C})$, 169.6 (C), 156.1 (C), 132.0 (C), $128.4(\mathrm{CH}), 116.4$ (CH), $94.1(\mathrm{CH}), 90.7(\mathrm{CH}, J 183 \mathrm{~Hz}, C H F), 70.4$ $(\mathrm{CH}), 70.0(\mathrm{CH}), 68.2(\mathrm{CH}), 67.9(\mathrm{CH}), 61.5\left(\mathrm{CH}_{2}\right)$, $44.9\left(\mathrm{CH}_{2}\right), 20.7\left(\mathrm{CH}_{3}\right), 20.6\left(\mathrm{CH}_{3}\right), 20.6\left(\mathrm{CH}_{3}\right), 20.6$ $\left(\mathrm{CH}_{3}\right), 8.4\left(\mathrm{CH}_{3}\right)$. IR (neat): $1759,1235,1043 \mathrm{~cm}^{-1}$. FABMS: $m / z \quad(\%) \quad 602 \quad\left(\mathrm{M}+\mathrm{TEA}+1^{+}, \quad 80\right), \quad 523$ $\left(\mathrm{M}+\mathrm{Na}^{+}, 90\right), 501\left(\mathrm{M}+1^{+}, 100\right)$; HRMS: calcd for $\mathrm{C}_{28} \mathrm{H}_{41} \mathrm{FNO}_{12}(\mathrm{M}+1)^{+}, 602.2613$; found, 602.2623.
3.8.2. Triethylammonium I(4-tetra- $O$-acetyl- $\alpha$-D-galactopyranosyloxy)phenyl|fluoroacetate (15b). Yield 94\% (oil), $R_{\mathrm{f}} 0.37$ (8:2 $\left.\mathrm{CHCl}_{3}-\mathrm{MeOH}\right) .{ }^{1} \mathrm{H}$ NMR $\left(\mathrm{CDCl}_{3}\right.$, $400 \mathrm{MHz}$ ): $\delta 7.42$ (d, $J 8.4 \mathrm{~Hz}, 2 \mathrm{H}$, aromatic), 7.00 (d, $J 8.4 \mathrm{~Hz}, 2 \mathrm{H}$, aromatic), $5.71(\mathrm{~d}, J 3.5 \mathrm{~Hz}, 1 \mathrm{H}, \mathrm{H}-1)$, $5.60(\mathrm{~d}, 1 \mathrm{H}, J 50.8 \mathrm{~Hz}, \mathrm{C} H \mathrm{~F}), 5.53-5.48(\mathrm{~m}, 2 \mathrm{H}, \mathrm{H}-$ $3+\mathrm{H}-4), 5.23$ (dd $J 10.7,3.5 \mathrm{~Hz}, 1 \mathrm{H}, \mathrm{H}-2), 4.29$ (dd, $J$ 6.7, $6.3 \mathrm{~Hz}, 1 \mathrm{H}, \mathrm{H}-5), 4.09-3.98$ (m, 2H, H-6+H-6'), 3.04 (q, J $7.3 \mathrm{~Hz}, 6 \mathrm{H}, \mathrm{TEA}), 2.12$ (s, 3H, OAc), 2.02 (s, 3H, OAc), 1.98 (s, 3H, OAc), 1.89 (s, 3H, OAc), $1.19(\mathrm{t}, J 7.3 \mathrm{~Hz}, 9 \mathrm{H}, \mathrm{TEA}) ;{ }^{13} \mathrm{C} \mathrm{NMR}\left(\mathrm{CDCl}_{3}\right.$, $100 \mathrm{MHz}): \delta 173.8(\mathrm{~d}, J 25 \mathrm{~Hz}, \mathrm{C}), 170.3(\mathrm{C}), 170.1$ (C), 170.1 (C), $170.0(\mathrm{C}), 156.4(\mathrm{C}), 131.9$ (d, J 21 Hz, C), $128.3(\mathrm{CH}), 116.6(\mathrm{CH}), 94.8(\mathrm{CH}), 90.5(\mathrm{~d}, J$ $182 \mathrm{~Hz}, \mathrm{CHF}), 67.8(\mathrm{CH}), 67.7(\mathrm{CH}), 67.4(\mathrm{CH}), 67.0$ $(\mathrm{CH}), 61.4\left(\mathrm{CH}_{2}\right), 45.0\left(\mathrm{CH}_{2}\right), 20.6\left(\mathrm{CH}_{3}\right), 20.6\left(\mathrm{CH}_{3}\right)$, $20.6\left(\mathrm{CH}_{3}\right), 20.5\left(\mathrm{CH}_{3}\right), 8.3\left(\mathrm{CH}_{3}\right)$. IR (neat): 1759 , 1222, $1076 \mathrm{~cm}^{-1}$. FABMS: $m / z(\%) 602\left(\mathrm{M}+\mathrm{TEA}+1^{+}\right.$, 89), $523\left(\mathrm{M}+\mathrm{Na}^{+}, 100\right), 501\left(\mathrm{M}+1^{+}, 90\right)$; HRMS: calcd for $\mathrm{C}_{28} \mathrm{H}_{41} \mathrm{FNO}_{12}(\mathrm{M}+1)^{+}, 602.2613$; found, 602.2620 .

3.8.3. Triethylammonium [(4-tri- $O$-acetyl- $\alpha$-L-fucopyranosyloxy)phenyl|fluoroacetate (15c). Yield $100 \%$ (oil), $R_{\mathrm{f}} \quad 0.37 \quad\left(8: 2 \quad \mathrm{CHCl}_{3}-\mathrm{MeOH}\right) .{ }^{1} \mathrm{H} \quad \mathrm{NMR} \quad\left(\mathrm{CDCl}_{3}\right.$, $400 \mathrm{MHz}): \delta 7.35$ (d, $J 8.4 \mathrm{~Hz}, 2 \mathrm{H}$, aromatic), $6.92(\mathrm{~d}$, $J 8.4 \mathrm{~Hz}, 2 \mathrm{H}$, aromatic), $5.60(\mathrm{~d}, J 3.6 \mathrm{~Hz}, 1 \mathrm{H}, \mathrm{H}-1)$, $5.52(\mathrm{~d}, J 49.6 \mathrm{~Hz}, 1 \mathrm{H}, \mathrm{C} H \mathrm{~F}), 5.44(\mathrm{dd}, J 10.9,3.3 \mathrm{~Hz}$, $1 \mathrm{H}, \mathrm{H}-3), 5.23$ (d, $J 3.3 \mathrm{~Hz}, 1 \mathrm{H}, \mathrm{H}-4), 5.14$ (dd, $J 10.9$, $3.6 \mathrm{~Hz}, 1 \mathrm{H}, \mathrm{H}-2), 4.14$ (q, J 6.4 Hz, $1 \mathrm{H}, \mathrm{H}-5), 2.98$ (q, $J 7.3 \mathrm{~Hz}, 6 \mathrm{H}, \mathrm{TEA}), 2.07$ (s, 3H, OAc), 1.96 (s, 3H, OAc), 1.90 (s, 3H, OAc), 1.15 (t, J 7.3 Hz, 9H, TEA), $1.00\left(\mathrm{~d}, J 6.4 \mathrm{~Hz}, 3 \mathrm{H}, \mathrm{CH}_{3}\right) ;{ }^{13} \mathrm{C}$ NMR $\left(\mathrm{CDCl}_{3}\right.$, $100 \mathrm{MHz}): \delta 174.3(\mathrm{C}), 170.3$ (C), $170.2(\mathrm{C}), 169.9(\mathrm{C})$, $156.3(\mathrm{C}), 131.5(\mathrm{C}), 128.2(\mathrm{CH}), 116.1(\mathrm{CH}), 94.5$ $(\mathrm{CH}), 90.8(\mathrm{~d}, J 180 \mathrm{~Hz}, \mathrm{CHF}), 70.6(\mathrm{CH}), 67.7(\mathrm{CH})$, $67.5(\mathrm{CH}), 65.1(\mathrm{CH}), 45.0\left(\mathrm{CH}_{2}\right), 20.5\left(\mathrm{CH}_{3}\right), 20.5$ $\left(\mathrm{CH}_{3}\right), 20.4\left(\mathrm{CH}_{3}\right), 15.6\left(\mathrm{CH}_{3}\right), 8.1\left(\mathrm{CH}_{3}\right)$. IR (neat): 3417, 2999, 1753, 1619, 1381, $1229 \mathrm{~cm}^{-1}$. FABMS: $\mathrm{m} / \mathrm{z}$ (\%) $544\left(\mathrm{M}+\mathrm{TEA}+1^{+}, \quad 8\right), 273$ (100); HRMS: calcd for $\mathrm{C}_{26} \mathrm{H}_{39} \mathrm{FNO}_{10}(\mathrm{M}+1)^{+}, 544.2558$; found, 544.2561 .

\subsection{General procedure for the preparation of fully protected probes $17 \mathrm{a}-\mathrm{c}$}

To a solution of the triethylammonium salt of $\alpha$-fluoroacid $15(0.16 \mathrm{mmol})$ and compound $16(0.20 \mathrm{mmol})$ in $3 \mathrm{~mL}$ of DMF were added HOBt $(27.5 \mathrm{mg}, 0.2 \mathrm{mmol})$, TEA $(0.25 \mathrm{mmol})$, and EDCI $(38.9 \mathrm{mg}, 0.20 \mathrm{mmol})$. The reaction mixture was stirred at $\mathrm{rt}$ for $24 \mathrm{~h}$. DMF was then removed under high vacuum. The residual oil was dissolved in $20 \mathrm{~mL}$ of EtOAc and washed with 5\% citric acid $(\times 3)$, satd $\mathrm{NaHCO}_{3}(\times 3)$, and brine. The organic phase was dried over anhyd $\mathrm{Na}_{2} \mathrm{SO}_{4}$, filtered, and concentrated. The biotinylated products $\mathbf{1 7}$ were 
obtained after silica gel column chromatography, eluting with 5:95 $\mathrm{MeOH}-\mathrm{CHCl}_{3}$.

3.9.1. $N$-[4-(Tetra- $O$-acetyl- $\alpha$-D-glucopyranosyloxy)phenyl]fluoroacetyl- $N^{\prime}$-biotinylcystamine (17a). Yield $65 \%, R_{\mathrm{f}}$ 0.30 (9:1 $\left.\mathrm{CHCl}_{3}-\mathrm{MeOH}\right), \mathrm{mp} 105-110{ }^{\circ} \mathrm{C} .{ }^{1} \mathrm{H}$ NMR $\left(\mathrm{CDCl}_{3}, 400 \mathrm{MHz}\right): \delta 7.37(\mathrm{~d}, J 8.3 \mathrm{~Hz}, 2 \mathrm{H}$, aromatic), 7.34 (br, $1 \mathrm{H}, \mathrm{NH}), 7.08$ (d, J $8.3 \mathrm{~Hz}, 2 \mathrm{H}$, aromatic), $6.84(\mathrm{br}, 1 \mathrm{H}, \mathrm{NH}), 6.50(\mathrm{br}, 1 \mathrm{H}, \mathrm{NH}), 5.77-5.62(\mathrm{~m}$, $4 \mathrm{H}), 5.12(\mathrm{dd}, J 9.8,9.4 \mathrm{~Hz}, 1 \mathrm{H}, \mathrm{H}-4), 5.00(\mathrm{dd}, J$ $10.3,3.6 \mathrm{~Hz}, 1 \mathrm{H}, \mathrm{H}-2), 4.45(\mathrm{~m}, 1 \mathrm{H}), 4.27(\mathrm{~m}, 1 \mathrm{H})$, $4.20(\mathrm{dd}, J 12.0,3.9 \mathrm{~Hz}, 1 \mathrm{H}, \mathrm{H}-6), 4.06-3.99(\mathrm{~m}, 2 \mathrm{H})$, 3.64-3.61 (m, 2H), 3.50-3.48 (m, 2H), $3.09(\mathrm{~m}, 1 \mathrm{H})$, $2.86-2.78(\mathrm{~m}, 5 \mathrm{H}), 2.67(\mathrm{~d}, J 12.7 \mathrm{~Hz}, 1 \mathrm{H}), 2.17-2.16$ $(\mathrm{m}, 2 \mathrm{H}), 2.02(\mathrm{~s}, 3 \mathrm{H}, \mathrm{OAc}), 2.01(\mathrm{~s}, 3 \mathrm{H}, \mathrm{OAc}), 2.00(\mathrm{~s}$, $3 \mathrm{H}, \mathrm{OAc}), 2.00$ (s, 3H, OAc), 1.65-1.62 (m, 4H), 1.23$1.20(\mathrm{~m}, 2 \mathrm{H}) ;{ }^{13} \mathrm{C} \mathrm{NMR}\left(\mathrm{CDCl}_{3}, 100 \mathrm{MHz}\right): \delta 173.6$ (C), 170.5 (C), 170.1 (C), 170.1 (C), 169.5 (C), 164.0 (C), $156.8(\mathrm{C}), 129.6(\mathrm{C}), 128.6(\mathrm{CH}), 116.6(\mathrm{CH}), 94.0$ $(\mathrm{CH}), 91.3(\mathrm{~d}, J 185 \mathrm{~Hz}, C \mathrm{HF}), 70.3(\mathrm{CH}), 69.9(\mathrm{CH})$, $68.1(\mathrm{CH}), 68.1(\mathrm{CH}), 61.7(\mathrm{CH}), 61.4\left(\mathrm{CH}_{2}\right), 60.1$ $(\mathrm{CH}), 55.6(\mathrm{CH}), 40.5\left(\mathrm{CH}_{2}\right), 38.2\left(\mathrm{CH}_{2}\right), 37.9\left(\mathrm{CH}_{2}\right)$, $37.2\left(\mathrm{CH}_{2}\right), 35.7\left(\mathrm{CH}_{2}\right), 29.6\left(\mathrm{CH}_{2}\right), 28.1\left(\mathrm{CH}_{2}\right), 27.9$ $\left(\mathrm{CH}_{2}\right), 25.5\left(\mathrm{CH}_{2}\right), 20.6\left(\mathrm{CH}_{3}\right), 20.6\left(\mathrm{CH}_{3}\right), 20.6$ $\left(\mathrm{CH}_{3}\right), 20.5\left(\mathrm{CH}_{3}\right)$. HRMS: calcd for $\mathrm{C}_{36} \mathrm{H}_{50} \mathrm{FN}_{4} \mathrm{O}_{13} \mathrm{~S}_{3}$ $(\mathrm{M}+1)^{+}, 861.2520$; found, 861.2517.

3.9.2. $\quad N$-[4-(Tetra- $O$-acetyl- $\alpha$-D-galactopyranosyloxy)phenyl]fluoroacetyl- $\boldsymbol{N}^{\prime}$-biotinylcystamine $\quad(\mathbf{1 7 b})$. Yield $65 \%, R_{\mathrm{f}} 0.17\left(9: 1 \mathrm{CHCl}_{3}-\mathrm{MeOH}\right), \mathrm{mp} 88-93{ }^{\circ} \mathrm{C} .{ }^{1} \mathrm{H}$ NMR $\left(\mathrm{CDCl}_{3}, 400 \mathrm{MHz}\right): \delta 7.36(\mathrm{~d}, J 8.3 \mathrm{~Hz}, 2 \mathrm{H}$, aromatic), 7.29 (br, $1 \mathrm{H}, \mathrm{NH}), 7.05$ (d, J $8.3 \mathrm{~Hz}, 2 \mathrm{H}$, aromatic), $6.93(\mathrm{br}, 1 \mathrm{H}, \mathrm{NH}), 6.61(\mathrm{br}, 1 \mathrm{H}, \mathrm{NH}), 5.75$ $5.53(\mathrm{~m}, 3 \mathrm{H}), 5.51(\mathrm{dd}, J 10.4,2.7 \mathrm{~Hz}, 1 \mathrm{H}, \mathrm{H}-3), 5.48$ (m, 1H, H-4), 5.23 (dd, J 10.4, $3.2 \mathrm{~Hz}, 1 \mathrm{H}, \mathrm{H}-2), 4.44$ (br, 1H), 4.28-4.25 (m, 2H), 4.09-4.00 (m, 2H), 3.69$3.55(\mathrm{~m}, 2 \mathrm{H}), 3.54-3.39(\mathrm{~m}, 2 \mathrm{H}), 3.08(\mathrm{~m}, 1 \mathrm{H}), 2.89$ $2.72(\mathrm{~m}, 5 \mathrm{H}), 2.66(\mathrm{~d}, J 11.9 \mathrm{~Hz}, 1 \mathrm{H}), 2.22-2.15(\mathrm{~m}$, $2 \mathrm{H}), 2.12$ (s, 3H, OAc), 2.02 (s, 3H, OAc), 1.98 (s, 3H, OAc), 1.89 (s, 3H, OAc), 1.74-1.51 (m, 4H), 1.48-1.31 $(\mathrm{m}, 2 \mathrm{H}) ;{ }^{13} \mathrm{C} \mathrm{NMR}\left(\mathrm{CDCl}_{3}, 100 \mathrm{MHz}\right): \delta 173.7(\mathrm{C})$, 170.3 (C), 170.3 (C), 170.1 (C), 170.0 (C), 169.0 (d, $J$ $34 \mathrm{~Hz}, \mathrm{C}), 164.1$ (C), 157.0 (C), 129.4 (d, $J 20 \mathrm{~Hz}, \mathrm{C}$ ), $128.6(\mathrm{CH}), 116.8(\mathrm{CH}), 94.6(\mathrm{CH}), 91.2(\mathrm{~d}, J 186 \mathrm{~Hz}$, CHF), $67.6(\mathrm{CH}), 67.6(\mathrm{CH}), 67.3(\mathrm{CH}), 67.1(\mathrm{CH})$, $61.6(\mathrm{CH}), 61.3\left(\mathrm{CH}_{2}\right), 60.1(\mathrm{CH}), 55.6(\mathrm{CH}), 40.5$ $\left(\mathrm{CH}_{2}\right), 38.2\left(\mathrm{CH}_{2}\right), 37.9\left(\mathrm{CH}_{2}\right), 37.2\left(\mathrm{CH}_{2}\right), 35.7\left(\mathrm{CH}_{2}\right)$, $29.6\left(\mathrm{CH}_{2}\right), 28.0\left(\mathrm{CH}_{2}\right), 27.9\left(\mathrm{CH}_{2}\right), 25.5\left(\mathrm{CH}_{2}\right), 20.6$ $\left(\mathrm{CH}_{3}\right), 20.6\left(\mathrm{CH}_{3}\right), 20.5\left(\mathrm{CH}_{3}\right), 20.5\left(\mathrm{CH}_{3}\right)$. HRMS: calcd for $\mathrm{C}_{36} \mathrm{H}_{50} \mathrm{FN}_{4} \mathrm{O}_{13} \mathrm{~S}_{3}(\mathrm{M}+1)^{+}, 861.2520$; found, 861.2517.

3.9.3. $\quad N$-[4-(Tri- $O$-acetyl- $\alpha$-L-fucopyranosyloxy)phenyl]fluoroacetyl- $\boldsymbol{N}^{\prime}$-biotinylcystamine (17c). Yield $67 \%, R_{\mathrm{f}}$ $0.25\left(9: 1 \mathrm{CHCl}_{3}-\mathrm{MeOH}\right), \operatorname{mp} 96-99^{\circ} \mathrm{C} .{ }^{1} \mathrm{H} \quad \mathrm{NMR}$ $\left(\mathrm{CDCl}_{3}, 400 \mathrm{MHz}\right): \delta 7.34$ (d, $J 8.5 \mathrm{~Hz}, 2 \mathrm{H}$, aromatic), $7.32(\mathrm{br}, 1 \mathrm{H}, \mathrm{NH}), 7.05(\mathrm{~d}, J 8.5 \mathrm{~Hz}, 2 \mathrm{H}$, aromatic), $6.86(\mathrm{br}, 1 \mathrm{H}, \mathrm{NH}), 6.52(\mathrm{~d}, J 7.6 \mathrm{~Hz}, 1 \mathrm{H}, \mathrm{NH}), 5.72$ $(\mathrm{d}, J 3.3 \mathrm{~Hz}, 1 \mathrm{H}, \mathrm{H}-1), 5.72(\mathrm{~d}, J 48.1 \mathrm{~Hz}, 1 \mathrm{H}, \mathrm{C} H \mathrm{~F})$, $5.63(\mathrm{br}, 1 \mathrm{H}, \mathrm{N} H), 5.53(\mathrm{dd}, J 10.9,3.3 \mathrm{~Hz}, 1 \mathrm{H}, \mathrm{H}-2)$, 5.33 (d, $J 3.5 \mathrm{~Hz}, 1 \mathrm{H}, \mathrm{H}-4), 5.23$ (dd, $J 10.9,3.5 \mathrm{~Hz}$, $1 \mathrm{H}, \mathrm{H}-3), 4.45(\mathrm{dd}, J 7.0,5.0 \mathrm{~Hz}, 1 \mathrm{H}), 4.27(\mathrm{~m}, 1 \mathrm{H})$, $4.20(\mathrm{q}, J 6.5 \mathrm{~Hz}, 1 \mathrm{H}), 3.68-3.63(\mathrm{~m}, 2 \mathrm{H}), 3.52-3.47$ $(\mathrm{m}, 2 \mathrm{H}), 3.09(\mathrm{~m}, 1 \mathrm{H}), 2.88-2.79(\mathrm{~m}, 5 \mathrm{H}), 2.67(\mathrm{~d}, J$ $12.8 \mathrm{~Hz}, 1 \mathrm{H}), 2.20-2.18(\mathrm{~m}, 2 \mathrm{H}), 2.16(\mathrm{~s}, 3 \mathrm{H}, \mathrm{OAc})$, $2.02(\mathrm{~s}, 3 \mathrm{H}, \mathrm{OAc}), 1.99(\mathrm{~s}, 3 \mathrm{H}, \mathrm{OAc}), 1.66-1.62(\mathrm{~m}$, $4 \mathrm{H}), 1.41-1.37(\mathrm{~m}, 2 \mathrm{H}), 1.08\left(\mathrm{~d}, J 6.5 \mathrm{~Hz}, 3 \mathrm{H}, \mathrm{CH}_{3}\right)$; ${ }^{13} \mathrm{C}$ NMR $\left(\mathrm{CDCl}_{3}, 100 \mathrm{MHz}\right): \delta 173.7$ (C), $170.5(\mathrm{C})$, 170.4 (C), 170.1 (C), 169.1 (d, J $23 \mathrm{~Hz}, \mathrm{C}$ ), 164.0 (C), $157.4(\mathrm{C}), 128.9(\mathrm{C}), 128.6(\mathrm{CH}), 116.5(\mathrm{CH}), 94.6$ $(\mathrm{CH}), 91.3(\mathrm{~d}, J 192 \mathrm{~Hz}, C H F), 70.8(\mathrm{CH}), 67.8(\mathrm{CH})$, $67.7(\mathrm{CH}), 65.5(\mathrm{CH}), 61.7(\mathrm{CH}), 60.1(\mathrm{CH}), 55.6$ $(\mathrm{CH}), 40.5\left(\mathrm{CH}_{2}\right), 38.2\left(\mathrm{CH}_{2}\right), 38.0\left(\mathrm{CH}_{2}\right), 37.2\left(\mathrm{CH}_{2}\right)$, $35.7\left(\mathrm{CH}_{2}\right), 29.6\left(\mathrm{CH}_{2}\right), 28.0\left(\mathrm{CH}_{2}\right), 25.5\left(\mathrm{CH}_{2}\right), 20.7$ $\left(\mathrm{CH}_{3}\right), 20.7\left(\mathrm{CH}_{3}\right), 20.6\left(\mathrm{CH}_{3}\right), 15.8\left(\mathrm{CH}_{3}\right)$. HRMS: calcd for $\mathrm{C}_{34} \mathrm{H}_{48} \mathrm{FN}_{4} \mathrm{O}_{11} \mathrm{~S}_{3}(\mathrm{M}+1)^{+} 803.2466$, found, 803.2455.

\subsection{General procedure for the preparation of probes $18 \mathrm{a}-\mathrm{c}$}

To a solution of biotinylated compound $17(0.10 \mathrm{mmol})$ in $3 \mathrm{~mL}$ of $\mathrm{MeOH}$ was added $50 \mathrm{mg}$ of $\mathrm{Na}_{2} \mathrm{CO}_{3}$. The mixture was stirred at $\mathrm{rt}$ for $1 \mathrm{~h}$ and filtered through Celite 535, and the filtrate was concentrated. The target probes 18a-c were obtained after silica gel column chromatography eluting with $\mathrm{CHCl}_{3}-\mathrm{MeOH}$ (7:3).

3.10.1. $N$-Biotinyl- $N^{\prime}$-[4-( $\alpha$-D-glucopyranosyloxy)phenyl]fluoroacetylcystamine (18a). Yield 45\%, $R_{\mathrm{f}} 0.30 \quad(7: 3$ $\mathrm{CHCl}_{3}-\mathrm{MeOH}$ ), mp $144-147{ }^{\circ} \mathrm{C} .{ }^{1} \mathrm{H}$ NMR (DMSO- $d_{6}$, $400 \mathrm{MHz}$ ): $\delta 8.62$ (br, $1 \mathrm{H}$, exchangeable $\mathrm{H}), 8.00(\mathrm{br}$, $1 \mathrm{H}$, exchangeable $\mathrm{H}), 7.36(\mathrm{~d}, J 8.1 \mathrm{~Hz}, 2 \mathrm{H}$, aromatic), $7.11(\mathrm{~d}, J 8.1 \mathrm{~Hz}, 2 \mathrm{H}$, aromatic), 6.43 (br, $1 \mathrm{H}$, exchangeable $\mathrm{H}), 6.37(\mathrm{br}, 1 \mathrm{H}$, exchangeable $\mathrm{H}), 5.80(\mathrm{~d}, J$ $47.8 \mathrm{~Hz}, 1 \mathrm{H}, \mathrm{CHF}$ ), 5.40 (br, $1 \mathrm{H}, \mathrm{H}-1), 5.09$ (br, $1 \mathrm{H}$, exchangeable $\mathrm{H}), 5.05-4.91(\mathrm{br}, 2 \mathrm{H}$, exchangeable $\mathrm{H}$ ), $4.48(\mathrm{br}, 1 \mathrm{H}$, exchangeable $\mathrm{H}), 4.29(\mathrm{~m}, 1 \mathrm{H}), 4.11(\mathrm{~m}$, $1 \mathrm{H}), 3.64-3.22(\mathrm{~m}, 9 \mathrm{H}), 3.17(\mathrm{~m}, 1 \mathrm{H}), 3.08(\mathrm{~m}, 1 \mathrm{H})$, $2.85-2.73(\mathrm{~m}, 5 \mathrm{H}), 2.56(\mathrm{~d}, J 12.4 \mathrm{~Hz}, 1 \mathrm{H}), 2.05(\mathrm{t}, J$ $6.8 \mathrm{~Hz}, 2 \mathrm{H}), 1.65-1.39(\mathrm{~m}, 4 \mathrm{H}), 1.38-1.21(\mathrm{~m}, 2 \mathrm{H}) ;{ }^{13} \mathrm{C}$ NMR (DMSO- $\left.d_{6}, 100 \mathrm{MHz}\right): \delta 172.5(\mathrm{C}), 168.4(\mathrm{~d}, J$ $24 \mathrm{~Hz}, \mathrm{C}), 162.9$ (C), 158.1 (C), 129.3 (C), $129.1(\mathrm{CH})$, $117.0(\mathrm{CH}), 98.0(\mathrm{CH}), 90.9(\mathrm{~d}, J 187 \mathrm{~Hz}, C \mathrm{HF}), 74.0$ $(\mathrm{CH}), 73.2(\mathrm{CH}), 71.7(\mathrm{CH}), 70.1(\mathrm{CH}), 61.3(\mathrm{CH})$, $60.9\left(\mathrm{CH}_{2}\right), 59.4(\mathrm{CH}), 55.7(\mathrm{CH}), 40.6\left(\mathrm{CH}_{2}\right), 38.8$ $\left(\mathrm{CH}_{2}\right), 38.5\left(\mathrm{CH}_{2}\right), 38.1\left(\mathrm{CH}_{2}\right), 37.5\left(\mathrm{CH}_{2}\right), 35.4$

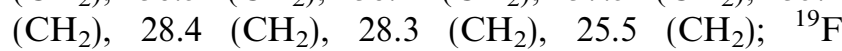
NMR (DMSO- $\left.d_{6}, \quad 400 \mathrm{MHz}\right): \delta-165.2 \quad(\mathrm{~d}, \quad J$ $53.6 \mathrm{~Hz}),-165.5(\mathrm{~d}, J 50.4 \mathrm{~Hz})$. FABMS: $m / z(\%) 715$ $\left(\mathrm{M}+\mathrm{Na}^{+}, 37\right), 693\left(\mathrm{M}+1^{+}, 26\right), 605$ (100); HRMS: 
calcd for $\mathrm{C}_{28} \mathrm{H}_{42} \mathrm{FN}_{4} \mathrm{O}_{9} \mathrm{~S}_{3}(\mathrm{M}+1)^{+}, 693.2098$; found, 693.2098 .

3.10.2. $\quad N$-Biotinyl- $N^{\prime}-[4-(\alpha-D$-galactopyranosyloxy)phenyl|fluoroacetylcystamine (18b). Yield $50 \%, R_{\mathrm{f}} 0.30$ $\left(7: 3 \mathrm{CHCl}_{3}-\mathrm{MeOH}\right), \quad \mathrm{mp} \quad 124-127^{\circ} \mathrm{C} . \quad{ }^{1} \mathrm{H} \quad \mathrm{NMR}$ (DMSO- $\left.d_{6}, 400 \mathrm{MHz}\right): \delta 8.62(\mathrm{br}, 1 \mathrm{H}$, exchangeable $\mathrm{H}), 7.99(\mathrm{br}, 1 \mathrm{H}$, exchangeable $\mathrm{H}), 7.35(\mathrm{~d}, J 8.4 \mathrm{~Hz}$, $2 \mathrm{H}$, aromatic), 7.09 (d, J $8.4 \mathrm{~Hz}, 2 \mathrm{H}$, aromatic), 6.43 (br, $1 \mathrm{H}$, exchangeable $\mathrm{H}$ ), 6.36 (br, $1 \mathrm{H}$, exchangeable $\mathrm{H}), 5.80(\mathrm{~d}, J 47.9 \mathrm{~Hz}, 1 \mathrm{H}, \mathrm{CHF}), 5.74(\mathrm{br}, 1 \mathrm{H}), 4.91$ $(\mathrm{d}, J 5.5 \mathrm{~Hz}, 1 \mathrm{H}$, exchangeable $\mathrm{H}), 4.75(\mathrm{br}, 1 \mathrm{H}$, exchangeable $\mathrm{H}), 4.56$ (br, $1 \mathrm{H}$, exchangeable $\mathrm{H}), 4.53$ (br, 1H, exchangeable $\mathrm{H}), 4.29(\mathrm{~m}, 1 \mathrm{H}), 4.11(\mathrm{~m}, 1 \mathrm{H})$, 3.76-3.73 (m, 2H), 3.65-3.28 (m, 8H), $3.09(\mathrm{~m}, 1 \mathrm{H})$, $2.85-2.73(\mathrm{~m}, 5 \mathrm{H}), 2.56(\mathrm{~d}, J 8.1 \mathrm{~Hz}, 1 \mathrm{H}), 2.06(\mathrm{t}, J$ $7.3 \mathrm{~Hz}, 2 \mathrm{H}), 1.49(\mathrm{~m}, 1 \mathrm{H}), 1.45-1.40(\mathrm{~m}, 3 \mathrm{H}), 1.37-$ $1.22(\mathrm{~m}, 2 \mathrm{H}) ;{ }^{13} \mathrm{C}$ NMR (DMSO- $\left.d_{6}, 100 \mathrm{MHz}\right): \delta$ 172.7 (C), 168.7 (d, J $24 \mathrm{~Hz}, \mathrm{C}$ ), 163.2 (C), 158.5 (C), $129.3(\mathrm{C}), 129.3(\mathrm{CH}), 117.2(\mathrm{CH}), 98.5(\mathrm{CH}), 91.2(\mathrm{~d}$, $J 185 \mathrm{~Hz}, C \mathrm{HF}), 72.8(\mathrm{CH}), 69.8(\mathrm{CH}), 68.9(\mathrm{CH})$, $68.3(\mathrm{CH}), 61.5(\mathrm{CH}), 60.6\left(\mathrm{CH}_{2}\right), 59.6(\mathrm{CH}), 55.9$ $(\mathrm{CH}), 40.3\left(\mathrm{CH}_{2}\right), 38.3\left(\mathrm{CH}_{2}\right), 38.2\left(\mathrm{CH}_{2}\right), 37.7\left(\mathrm{CH}_{2}\right)$, $37.2\left(\mathrm{CH}_{2}\right), 35.6\left(\mathrm{CH}_{2}\right), 28.6\left(\mathrm{CH}_{2}\right), 28.5\left(\mathrm{CH}_{2}\right), 25.7$ $\left(\mathrm{CH}_{2}\right) ;{ }^{19} \mathrm{~F}$ NMR (DMSO-d $\left.6,400 \mathrm{MHz}\right): \delta-165.0(\mathrm{~d}$, $J 50.4 \mathrm{~Hz}),-165.3(\mathrm{~d}, J 50.4 \mathrm{~Hz})$. FABMS: $m / z(\%)$ $693\left(\mathrm{M}+1^{+}, 57\right), 605$ (100); HRMS: calcd for $\mathrm{C}_{28} \mathrm{H}_{42} \mathrm{FN}_{4} \mathrm{O}_{9} \mathrm{~S}_{3}(\mathrm{M}+1)^{+}$, 693.2098; found, 693.2098.

3.10.3. $N$-Biotinyl- $N^{\prime}-[4-(\alpha$-L-fucopyranosyloxy)phenyl]fluoroacetylcystamine (18c). Yield $55 \%, R_{\mathrm{f}} 0.25(8: 2$ $\mathrm{CHCl}_{3}-\mathrm{MeOH}$ ). ${ }^{1} \mathrm{H}$ NMR (DMSO- $d_{6}, 400 \mathrm{MHz}$ ): $\delta$ 8.61 (br, $1 \mathrm{H}$, exchangeable $\mathrm{H}), 7.99$ (br, $1 \mathrm{H}$, exchangeable $\mathrm{H}), 7.36(\mathrm{~d}, J 8.3 \mathrm{~Hz}, 2 \mathrm{H}$, aromatic), $7.06(\mathrm{~d}, J$ $8.3 \mathrm{~Hz}, 2 \mathrm{H}$, aromatic), $6.43(\mathrm{br}, 1 \mathrm{H}$, exchangeable $\mathrm{H})$, 6.36 (br, 1H, exchangeable H), $5.80(\mathrm{~d}, J 47.4 \mathrm{~Hz}, 1 \mathrm{H}$, $\mathrm{CHF}), 5.42(\mathrm{br}, 1 \mathrm{H}, \mathrm{H}-1), 4.86$ (d, J $4.7 \mathrm{~Hz}, 1 \mathrm{H}$, exchangeable $\mathrm{H}), 4.70$ (br, $1 \mathrm{H}$, exchangeable $\mathrm{H}), 4.59$ $(\mathrm{d}, J 2.6 \mathrm{~Hz}, 1 \mathrm{H}$, exchangeable $\mathrm{H}), 4.29(\mathrm{~m}, 1 \mathrm{H}), 4.11$ $(\mathrm{m}, 1 \mathrm{H}), 3.85(\mathrm{q}, J 6.3 \mathrm{~Hz}, 1 \mathrm{H}), 3.80-3.69(\mathrm{~m}, 2 \mathrm{H})$, $3.54(\mathrm{~m}, 1 \mathrm{H}), 3.50-3.38(\mathrm{~m}, 2 \mathrm{H}), 3.33-3.23(\mathrm{~m}, 2 \mathrm{H})$, $3.09(\mathrm{~m}, 1 \mathrm{H}), 2.85-2.73(\mathrm{~m}, 5 \mathrm{H}), 2.56(\mathrm{~d}, J 12.1 \mathrm{~Hz}$, $1 \mathrm{H}), 2.09-2.02(\mathrm{~m}, 2 \mathrm{H}), 1.59-1.39(\mathrm{~m}, 4 \mathrm{H}), 1.32-1.02$ $(\mathrm{m}, 2 \mathrm{H}), 1.03(\mathrm{~d}, J 6.3 \mathrm{~Hz}, 3 \mathrm{H}) ;{ }^{13} \mathrm{C}$ NMR (DMSO- $d_{6}$, $100 \mathrm{MHz}): \delta 1727$ (C), 168.7 (d, J $24 \mathrm{~Hz}, \mathrm{C}), 163.2$ (C), $158.4(\mathrm{C}), 129.4(\mathrm{CH}), 129.3(\mathrm{C}), 116.9(\mathrm{CH}), 98.3$ $(\mathrm{CH}), 91.1(\mathrm{~d}, J 182 \mathrm{~Hz}, C H F), 71.8(\mathrm{CH}), 69.9(\mathrm{CH})$, $68.0(\mathrm{CH}), 67.7(\mathrm{CH}), 61.5(\mathrm{CH}), 59.6(\mathrm{CH}), 55.9$ $(\mathrm{CH}), 40.3\left(\mathrm{CH}_{2}\right), 38.3\left(\mathrm{CH}_{2}\right), 38.2\left(\mathrm{CH}_{2}\right), 37.7\left(\mathrm{CH}_{2}\right)$, $37.2\left(\mathrm{CH}_{2}\right), 35.6\left(\mathrm{CH}_{2}\right), 28.6\left(\mathrm{CH}_{2}\right), 28.5\left(\mathrm{CH}_{2}\right), 25.7$ $\left(\mathrm{CH}_{2}\right), 16.9\left(\mathrm{CH}_{3}\right) ;{ }^{19} \mathrm{~F}$ NMR (DMSO- $\left.d_{6}, 400 \mathrm{MHz}\right): \delta$ -165.0 (d, $J 50.4 \mathrm{~Hz}),-165.3$ (d, $J 50.4 \mathrm{~Hz})$. FABMS: $\mathrm{m} / \mathrm{z}(\%) 677\left(\mathrm{M}+1^{+}, 67\right), 605$ (100); HRMS: calcd for $\mathrm{C}_{28} \mathrm{H}_{42} \mathrm{FN}_{4} \mathrm{O}_{8} \mathrm{~S}_{3} \quad(\mathrm{M}+1)^{+}, \quad 677.2146 ;$ found, 677.2156 .

\section{Acknowledgements}

This work was supported by the National Science Council (NSC 93-3112-B-002-001 to L.-C.L.). We thank Professor Yulin Lam for reading the manuscript.

\section{Supplementary data}

Supplementary data associated with this article can be found, in the online version, at doi:10.1016/j.carres. 2005.12.005.

\section{References}

1. Feizi, T. Nature 1985, 314, 53-57.

2. Lasky, L. A. Science 1992, 258, 964-969.

3. Varki, A. Glycobiology 1993, 3, 97-130.

4. Kolter, T.; Sears, P.; Wong, C.-H. Cell. Mol. Life Sci. 1998, 54, 223-252.

5. Herscovics, A. Biochim. Biophys. Acta 1999, 1473, 96-107.

6. Parodi, A. J. Biochem. J. 2000, 348, 1-13.

7. Taylor, G. Nature 1993, 363, 401-402.

8. Babu, Y. S.; Chand, P.; Bantia, S.; Kotian, P.; Dehghani, A.; El-Kattan, Y.; Lin, T. H.; Hutchison, T. L.; Elliott, A. J.; Parker, C. D.; Ananth, S. L.; Horn, L. L.; Laver, G. W.; Montgomery, J. A. J. Med. Chem. 2000, 43, 34823486.

9. Asano, N. Glycobiology 2003, 13, 93R-104R.

10. Cravatt, B. F.; Sorensen, E. J. Curr. Opin. Chem. Biol. 2000, 4, 663-668.

11. Adam, G. C.; Sorensen, E. J.; Cravatt, B. F. Mol. Cell. Proteomics 2002, 1, 781-790.

12. Jeffrey, D. A.; Bogyo, M. Curr. Opin. Biotechnol. 2003, 14, 87-95.

13. Campbell, D. A.; Szardenings, A. K. Curr. Opin. Chem. Biol. 2003, 7, 296-303.

14. Janda, K. D.; Lo, L.-C.; Lo, C.-H. L.; Sim, M.-M.; Wang, R.; Wong, C.-H.; Lerner, R. A. Science 1997, 275, 945948.

15. Ichikawa, M.; Ichikawa, Y. Bioorg. Med. Chem. Lett. 2001, 11, 1769-1773.

16. Tsai, C.-S.; Li, Y.-K.; Lo, L.-C. Org. Lett. 2002, 4, 36073610 .

17. Kurogochi, M.; Nishimura, S.; Lee, Y. C. J. Biol. Chem. 2004, 279, 44704-44712.

18. Vocadlo, D. J.; Bertozzi, C. R. Angew. Chem., Int. Ed. 2004, 43, 5338-5342.

19. Hekmat, O.; Kim, Y.-W.; Williams, S. J.; He, S.; Withers, S. G. J. Biol. Chem. 2005, 280, 35126-35135.

20. Lo, L.-C.; Wang, H.-Y.; Wang, Z.-J. J. Chin. Chem. Soc. 1999, 46, 715-718.

21. Lo, L.-C.; Pang, T.-L.; Kuo, C.-H.; Chiang, Y.-L.; Wang, H.-Y.; Lin, J.-J. J. Proteome Res. 2002, 1, 35-40.

22. Lo, L.-C.; Chiang, Y.-L.; Kuo, C.-H.; Liao, H.-K.; Chen, Y.-J.; Lin, J.-J. Biochem. Biophys. Res. Commun. 2005, 326, 30-35.

23. Paulsen, H. Angew. Chem., Int. Ed. 1982, 21, 155-173.

24. Danishefsky, S. J.; McClure, K. F.; Randolph, J. T.; Ruggeri, R. B. Science 1993, 260, 1307-1309.

25. Rademann, J.; Geyer, A.; Schmidt, R. R. Angew. Chem., Int. Ed. 1998, 37, 1241-1245.

26. Sears, P.; Wong, C.-H. Science 2001, 2915, 2344-2350. 
27. Kim, J.-H.; Yang, H.; Boons, G.-J. Angew. Chem., Int. Ed. 2005, 44, 947-949.

28. Yamaguchi, M.; Horiguchi, A.; Fukuda, A.; Minami, T. $J$. Chem. Soc., Perkin Trans. 1 1990, 1079-1082.

29. Lo, L.-C.; Lo, C.-H. L.; Janda, K. D.; Kassel, D. B.; Raushel, F. M. Bioorg. Med. Chem. Lett. 1996, 6, 2117-2120.

30. Zhu, Q.; Huang, G. Y. J.; Yao, S. Q. Tetrahedron Lett. 2003, 44, 2669-2672.
31. Thomas, R. M.; Iyengar, D. S. Synth. Commun. 1999, 29 2507-2514.

32. Rye, C. S.; Withers, S. G. J. Am. Chem. Soc. 2002, 124 , 9756-9767.

33. Nobrega, C.; Vazquez, J. T. Tetrahedron: Asymmetry 2003, 14, 2793-2802.

34. Li, H.-Y.; Liu, Y.; Fang, K.; Nakanishi, K. Chem. Commun. (Cambridge) 1999, 365-366. 